\title{
Axon Overproduction and Elimination in the Corpus Callosum of the Developing Rhesus Monkey
}

\author{
A.-S. LaMantia and P. Rakic \\ Section of Neuroanatomy, Yale University School of Medicine, New Haven, Connecticut 06510
}

\begin{abstract}
We have studied the cytological and quantitative aspects of axon addition and elimination in the corpus callosum of the developing rhesus monkey. Electron microscopic analysis reveals that during fetal development the number of callosal axons increases from 4 million at embryonic day 65 (E65) to 188 million at birth (E165). Thus, the number of callosal axons in newborn monkeys exceeds the number present in the adult (an average of 56 million; LaMantia and Rakic, 1990a) by at least 3.5 times. Although there is some variability among the 11 fetal and newborn monkeys examined, there appears to be a progressive increase in the total number of callosal axons from midgestation through birth. The presence and numbers of growth cones from E65 through birth suggests that axon addition occurs exclusively during this period. There is no ultrastructural or quantitative indication of postnatal axon addition.
\end{abstract}

After birth, about $70 \%$ of the axons in the callosum are eliminated in 2 phases. During the first phase, which includes the first 3 postnatal weeks, approximately 80 million axons are lost at an estimated rate of $4.4 \mathrm{million} / \mathrm{d}$ or $50 / \mathrm{sec}$. During the second phase, which continues for the following 3 months, an additional $\mathbf{5 0}$ million axons are eliminated at a rate of $\mathbf{0 . 5}$ million/d or $5 / \mathrm{sec}$ until the adult value is reached. A discontinuous distribution of different classes of axons along the anterior-posterior axis of the tract reminiscent of the pattern seen in the adult is detectable before the onset of the first phase of axon elimination.

Since the basic topography and terminal field patterns of callosal projections are well established before birth in all regions of the monkey cortex examined so far (GoldmanRakic et al., 1983; Killackey and Chalupa, 1986; Dehay et al., 1988; Schwartz and Goldman-Rakic, 1990), we conclude that the massive postnatal elimination of callosal axons described here is unlikely to play a significant role in the development of discretely patterned callosal projection zones or their columnar terminations. The coincidence of axon elimination and the increase in synaptic density throughout the primate cerebral cortex during the first 6 postnatal months

\footnotetext{
Received Jan. 9, 1990; revised Feb. 6, 1990; accepted Feb. 26, 1990.

We thank Robert Williams for helpful discussions during all phases of this study, Douglas Frost for advice on statistical analysis, Joe Musco for excellent technical assistance, and Susan Eads and Barbara Hartman for typing the manuscript. Supported by NS1 14841 and a Senator Jacob Javits Center for Neuroscience Grant (NS22807).

Correspondence should be addressed to A.-S. LaMantia at his present address: Department of Neurobiology, Duke University Medical Center, Box 3209, Durham, NC 27710.

Copyright (C) 1990 Society for Neuroscience $0270-6474 / 90 / 072156-20 \$ 03.00 / 0$
}

(Rakic et al., 1986), however, suggests that supernumerary axons may be lost during a process that results in the local proliferation of synapses from a subset of initial interhemispheric projections.

The corpus callosum is the largest and most prominent axonal pathway in the mammalian cerebral hemispheres. In spite of a great deal of interest in the development and function of interhemispheric connections made via this pathway, little is known about the development and organization of the tract itself. The developmental history of an axonal pathway can often illuminate the processes by which the related classes of neurons make their connections. For example, a great deal has been learned about the development of retinal projections by determining when the adult number of optic axons is established and how different types of axons become limited to distinct regions of the optic nerve or tract (Rager and Rager, 1976; Easter et al., 1981; Rakic and Riley, 1983; Walsh and Guillery, 1985; Williams and Rakic, 1985; Williams et al., 1986). In the developing optic nerve, changes in the number and distribution of axons are often accompanied by elimination of the neurons that give rise to these axons (Linden and Perry, 1982; Perry et al., 1983) or changes in the patterns of terminal fields in the axons' target region (Rakic, 1976, 1986). It is possible that similar phenomena occur in axon pathways in other regions of the mammalian CNS (Rakic and Goldman-Rakic, 1982; Cowan et al., 1984); however, outside of the visual system there is little quantitative data to confirm this assumption.

Quantitative data that address the number and types of axons in the developing corpus callosum are essential for a better understanding of the mechanisms involved in the development of interhemispheric connections in the mammalian cortex. Previous studies using anterograde and retrograde tracing methods in the developing cat and rat have demonstrated that some cortical neurons initially send axon branches toward the contralateral hemisphere via the corpus callosum and subsequently lose this interhemispheric collateral as adult patterns of connectivity emerge (Innocenti et al., 1977, 1986; Ivy et al., 1979; O'Leary et al., 1981; Ivy and Killacky, 1982; Feng and Brugge, 1983; Olavarria and Van Sluyters, 1985). Quantitative analysis of the numbers of axons in the corpus callosum of the developing cat indicates that cortical projection axons are lost during early postnatal development at the same time as transient callosal neurons are disappearing from primary visual, somatosensory, auditory, and motor cortices (Koeppel and Innocenti, 1983; Berbel and Innocenti, 1988). However, a similar study in the rat failed to detect any elimination of axons during the time 
that "exuberant" projections can be detected using retrograde tracing techniques (Gravel et al., 1990).

There are some reasons to doubt that processes similar to those described for the cat and rat are involved in the development of interhemispheric connections in primates, where the number and diversity of callosal connections are greatest (see LaMantia and Rakic, 1990a, for review).

A quantitative assessment of the extent of axon overproduction and elimination in the corpus callosum of the developing rhesus monkey, interpreted in the light of recent observations of the development of patterns of interhemispheric connectivity, might help clarify some apparent differences in the development of callosal connections in primate and nonprimate species. Several investigations of callosal projections in the developing monkey cortex indicate that the genesis of patterned callosal connections in primates may not rely on a period of postnatal exuberance similar to that described using retrograde tracers in cats and rats. For example, in the monkey primary visual cortex, a widespread pattern of callosal projections cannot be detected at any time, either before or after birth (Dehay et al., 1986, 1988; Chalupa and Killackey, 1989). In all other cortical areas examined thus far, the mature pattern of callosal projections can be seen at least 1 month before birth (Goldman-Rakic et al., 1983; Killackey and Chalupa, 1986).

The extent of "exuberant" phenomena at earlier fetal ages is not completely clear. In the somatosensory cortex and visual association cortex of fetal monkeys between E108 and E126 the distribution of retrogradely labeled callosal neurons appears more widespread than that in older fetuses (Killackey and Chalupa, 1986; Dehay et al., 1988). In contrast, when the pattern of retrogradely labeled callosal neurons in the prefrontal cortex of fetal monkeys between E80 and E125 is analyzed quantitatively, a discontinuous distribution of ncurons reminiscent of that in the adult is found (Schwartz and Goldman-Rakic, in press). Furthermore, tracing studies in developing monkey prefrontal and parietal association cortices in which the injection size is corrected for brain size failed to reveal projection neurons with widely divergent collaterals in fetal and newborn animals (Schwartz and Goldman-Rakic, 1982, 1990; Goldman-Rakic et al., 1983) as described for the infant cal and rat (Innocenti, 1981; O'Leary et al., 1981; Ivy and Killackey, 1982). However, the incidence of cells with a callosal axon and short collateral axon in the ipsilateral hemisphere has been reported in the somatosensory cortex of fetal monkeys between E108 and E1 15 (Chalupa and Killackey, 1989).

Clearly, there are significant differences between the ways in which adult patterns of callosal connectivity emerge in primates, carnivores, and rodents. Depending on the region of the cortex examined in the monkey, cxubcrant phenomena arc cither not present, or seem to occur at a much earlier time than that reported in other species. In the present study, we characterize the magnitude and timing of axon addition and elimination by determining the numbers of axons present in the rhesus monkey corpus callosum at all stages of development. The details of the cytological and quantitative development of this axon pathway reinforce the conclusion that there are differences in the processes by which interhemispheric connections are made in the primate neocortex and those in other species.

\section{Materials and Methods}

Tissue preparation. Fetal, neonatal, and juvenile rhesus monkeys ( $\mathrm{Ma}$ caca mulatta) were obtained from the Yale primate facility and the New
England Regional Primate Center (South Marlboro, MA). Twenty-two pre- and postnatal monkeys of precisely known age were examined in this study. The age, in days, of each monkey was calculated using the date of conception as embryonic day 0 (E0) and the date of birth (E165, all animals delivered by caesarian section) as postnatal day 0 (P0). For caesarian delivery of fetal monkeys, pregnant mothers were anesthetized by inhalation of a mixture of halothane and oxygen. Within a minute after delivery, the fetuses were perfused through the heart with buffered saline $(0.1 \mathrm{M}$ NaPO 4 buffer, $\mathrm{pH} 7.4,0.9 \% \mathrm{NaCl})$ followed by fixation with a solution of $1.25 \%$ paraformaldehyde $/ 1.25 \%$ glutaraldehyde in $0.1 \mathrm{~m}$ PO4 buffer, $\mathrm{pH} 7.4$ and then $2.5 \%$ paraformaldehyde $/ 2.5 \%$ glutaraldehyde in $0.1 \mathrm{M}$ PO4 buffer at the same $\mathrm{pH}$ (Rakic, 1972). Both fixatives were saturated with an aqueous solution of $5 \% \mathrm{CaCl}_{2}$. Neonatal, juvenile, and adult monkeys were given an overdose of sodium pentobarbital and perfused as above.

Brains were removed from the skull immediately after perfusion and postfixed overnight in buffered aldehyde fixative. The following morning the brain was hemisected in the midsagittal plane, and the entire corpus callosum was removed from the right midsagittal surface as a single 1$2-m m$-thick slab. The remainder of the brain was prepared for parallel quantitative studies of the development of other cortical commissures (A.-S. LaMantia and P. Rakic, unpublished observations) as well as synaptogenesis and regulation of neuron number in the developing rhesus monkey visual system and cerebral cortex (Rakic and Riley, 1983; Rakic et al., 1986; Williams and Rakic, 1985, 1988; Zecevic et al., 1989). The entire callosal block was rinsed in phosphate buffer, postfixed in $\mathrm{OsO}_{4}$, and embedded whole in Epon-Araldite for ultramicrotomy, as described previously (LaMantia and Rakic, 1990a). All incubations were donc in small glass petri dishes to ensure that the blocks remained flat and did not break while being processed.

One micron sectioning and area estimation. A teflon-coated razor blade was used to divide the Epon-Araldite block containing the entire corpus callosum into smaller blocks. The large block was fractured with extreme care to ensure that no tissue was lost. Each small block was first sectioned at $1 \mu \mathrm{m}$ using a glass knife until a complete surface covered by a glia limitans could be detected at the dorsal and ventral aspects of the corpus callosum. These sections were stained with toluidine blue, coverslipped, and drawn with a camera lucida at a magnification of 50 $100 \times$. The midsagittal surface area of the corpus callosum was estimated as the sum of the areas of these drawings measured on a Zeiss MOPVideoplan II computerized planimeter. The drawings from postnatal specimens excluded the area occupied by the hippocampal commissure, which was analyzed scparatcly (LaMantia and Rakic, unpublished observations). It is important to note that the comparatively small number of axons in the hippocampal commissure (1.7 million at birth, 237,000 in the adult; LaMantia and Rakic, 1990) is well below the sampling error for the entire corpus callosum and thus does not complicate the quantitative analysis.

Sampling for axon density estimates. Systematic samples were taken to estimate mean axon density throughout the entire anterior-posterior length of the corpus callosum (Snedecor and Cochran, 1977). The basic procedure has been described in more detail elsewhere (LaMantia and Rakic, 1990) and has been modified slightly to accommodate this developmental study. The corpus callosum was divided into 10 sectors defined by one-tenth of the total anterior-posterior distance (Fig. 1). Samples were taken from every sector for animals aged $\mathrm{P0}$ and adults, or every other sector starting with sector 2 for animals at all other ages. The corpora callosa from animals aged E65, E72, and E85 were small enough to be sampled in their entirety. In all other animals the sampling region consisted of a $1.5-2.0 \mathrm{~mm}$ square area of the corpus callosum at the caudal boundary of each sector that was prepared for ultramicrotomy. Silver-gold sections were cut using a diamond knife, and these sections were placed on 300 mesh grids, stained with uranyl acetate and lead citrate, and studied in a JEOL $100 \mathrm{~S}$ electron microscope. The grid mesh was used as a guide for a systematic sample: the top left corner of every other grid opening in every other row was photographed going from the dorsal to ventral aspect of the section. Usually between 10 and 20 micrographs were taken for each sample. $\Lambda t$ the end of each sampling session a calibration grid was photographed at the same power as the sample micrographs.

Axon density was calculated for each sample by counting the number of axons in each micrograph within a rectangular "counting frame" of a standard area and orientation. Axons that intersected the top and right side margins as well as the upper right and left hand corners of the counting frame were included in the count for each micrograph to ensure 


\section{dorsal $\uparrow$}

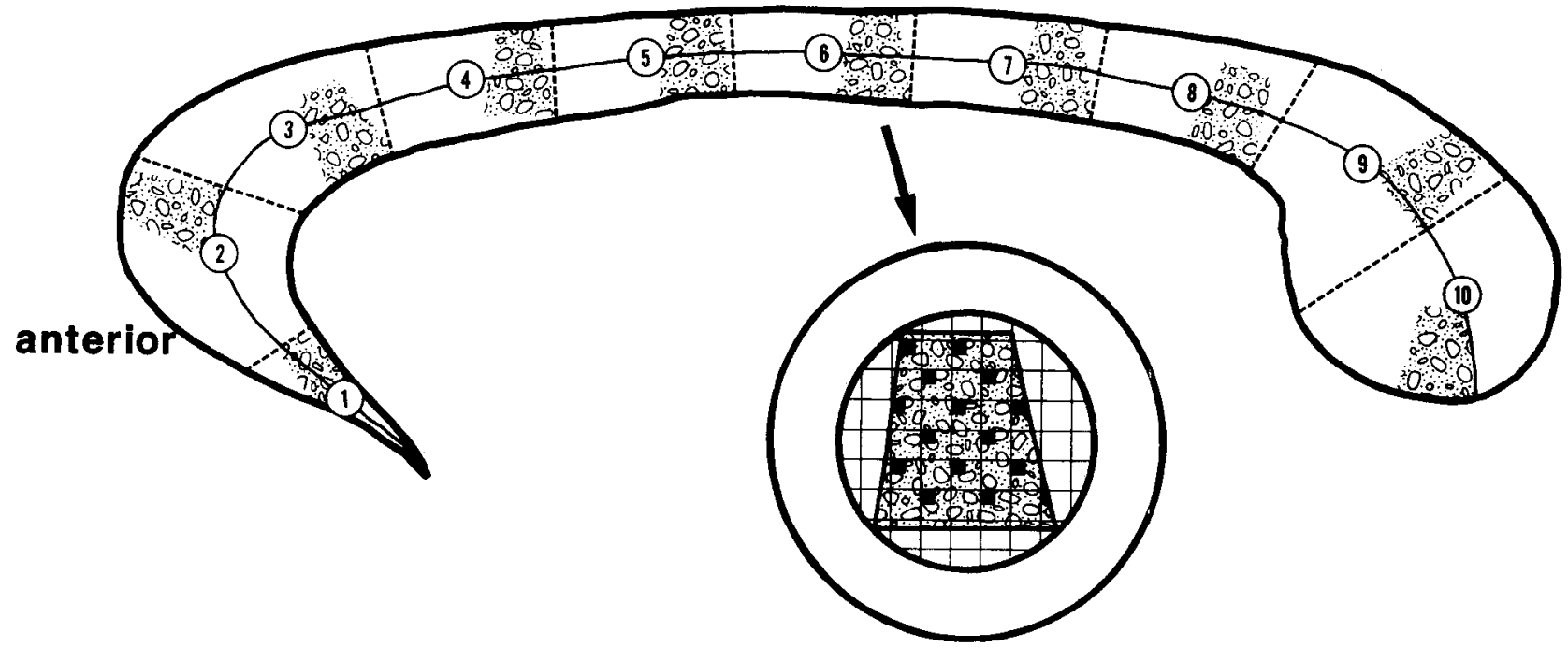

Figure 1. Diagram of the sampling strategy employed for estimating the number of axons in the corpus callosum. The length of each sector represents one tenth of the total anterior-posterior span of the corpus callosum at the midline, determined using a line drawn through the middle of the callosum as shown here. The size of each EM sampling region (hatched trapezoids) is approximately $1.5 \times 1.5 \mathrm{~mm}$. In all animals except for 2 (P0:1 and P0:2) only the even sectors were sampled for estimation of axon density.

that a standard area was sampled from micrograph to micrograph (Gunderson, 1977). The number of myelinated axons, unmyelinated axons, and growth-cone-like processes was recorded for each micrograph. The mean axon density for each sample was calculated by taking the average number of axons per micrograph, then dividing this number by the area enclosed within the counting frame, and finally standardizing this value to equal the number of axons $/ 100 \mu \mathrm{m}^{2}$.

Rationale for the "sector" method. The "sector method" described above ensures that regional differences in axon density will not be disproportionately sampled from individual to individual. It also allows more rigorous evaluation of regional differences during the course of development. Two factors assure the comparability of callosal sectors in animals of different ages. First, the sector divisions are based on total callosal length which increases in register with the area of the corpus callosum during gestation and early postnatal development (see Tables 1 and 3 and Results). Second, and most important, the identities of the sectors from animal to animal during development as well as in the adult proved to be remarkably consistent on the basis of comparisons of axon density, myelination, and axon diameter. Therefore the "sector" method increases the reliability of the axon number estimates.

Estimates of axon number. Because of the consistent differences in density between individual sectors (LaMantia and Rakic, 1990) a simple arithmetic mean cannot be used to assess axon density and total axon number in the corpus callosum. An accurate estimate can be obtained only by treating each geometrically defined sector as an individual sampling unit and summing the number of axons in each sector across the entire corpus callosum (LaMantia and Rakic, 1990). We have used this strategy to determine the total number of callosal axons for 2 newborn animals (P0: 1 and $\mathrm{P0}: 2$; see Table 3 ) where samples were taken from each of the 10 callosal sectors. In the remaining animals samples were drawn from every other sector beginning with sector 2 . This modification proved to be adequate for obtaining accurate estimates of axon number. Although at the outset it was not clear whether or not axon density would vary in the developing callosum in the same way as in the adult, our observations (see Results) demonstrate that this is indeed the case. Given the systematic variability in axon density between sectors in developing animals one can assume the following: sectors 1, 2, and 3 are high-density sectors with equivalent axon density values in any individual, and therefore if $d_{n}$ is the axon density for the $n$th sector $d_{1}=d_{2}=d_{3} ;$ sectors 4,5 , and 9 are intermediate-density sectors and therefore $d_{4}=d_{5}=d_{9}$; sectors $6,7,8$, and 10 are low-density sectors and therefore $d_{6}=d_{7}=d_{8}=d_{10}$. These assumptions proved valid for the corpus callosum at pre- and postnatal ages with the following exception: sector 10 has a uniquely high axon density during early post- natal life (see Table 4; Results). Therefore if axon density estimates for sectors $2,4,6,8$, and 10 are available, the following formula can be used to estimate total callosal axon number, Ncc:

$$
\begin{aligned}
\mathrm{Ncc}= & \sum d_{2}\left(A_{1}, A_{2}, A_{3}\right)+d_{4}\left(A_{4}, A_{5}, A_{9}\right)+d_{6} A_{6} \\
& +\left[\left(d_{6}+d_{8}\right) / 2\right]\left(A_{7}\right)+d_{8} A_{8}+d_{10} A_{10},
\end{aligned}
$$

where $A_{n}$ is the area of the appropriate sector.

Because of the organization of the primate corpus callosum and the sampling strategy employed, the most appropriate estimate of sampling error is based on a comparison of the variability that arises from the samples within each sector. The standard deviation from density estimates in each sector reflects the variability inherent in the sampling procedure rather than the variability between each sector, which is biologically significant and consistent from animal to animal. Therefore, the error estimate, $S$, that best reflects the variability in the sampling procedure used to determine axon density is equivalent to the SEM for axon density within each sector summed over all sectors sampled:

$$
S=\sqrt{\sum} W_{h 2}\left(s_{h 2} / n_{h}\right)
$$

where $W_{h}$ is the total number of micrographs counted from all sectors, $s_{h}$ is the standard deviation for each sector, with $n-1$ degrees of freedom, and $n_{t}$ is the number of micrographs counted from each sector.

Axon diameter measurements. Axon diameters were measured from the sample micrographs used for axon density estimates. A "measuring frame" of constant size and orientation was placed over 5-10 micrographs selected randomly from each sample set so that approximately $500-1000$ axons were measured from each region. The surface area of the axon without its myelin sheath was determined using a computerized morphomctric system (Zeiss MOP-Videoplan). The diameter of a callosal axon was calculated as the equivalent diameter of a circle with the area measured for that individual axon. The data were analyzed and sample means and errors were generated using the Videoplan's resident statistical analysis programs.

Serial section analysis. Two sets of serial sections were prepared from a $1.5 \mathrm{~mm}^{2}$ region in sectors 3 and 4 of the corpus callosum from the E88 specimen. This material was fixed and embedded as described above. Two series of silver-gold sections were cut from this block and placed on formvar coated slot grids. The first series had 150 consecutive sections, and the second had 180 consecutive sections. The orientation of each section on the grid was drawn, and the section number recorded. The grids were stained with uranyl acetate and lead citrate in an LKB ultrastainer automatic staining machine. Several regions were selected 
Table 1. Quantitative characteristics of the corpus callosum during prenatal development

\begin{tabular}{lcrrrrr} 
Age & $\begin{array}{l}\text { Length } \\
(\mathrm{mm})\end{array}$ & Area $\left(\mu \mathrm{m}^{2}\right)$ & $\begin{array}{l}\text { Axons/ } \\
100 \mu^{2}\end{array}$ & \multicolumn{1}{c}{$n$ axons } & $\begin{array}{l}\text { Mrror } \\
\%\end{array}$ & $\begin{array}{l}\text { Mean } \\
\text { myelinated } \\
\%\end{array}$ \\
\hline E65 & 3.64 & $1,200,000$ & 334 & $4,010,000$ & 8.0 & 0 \\
E72 & 4.00 & $1,490,000$ & 454 & $6,770,000$ & 14.0 & 0 \\
E85 & 14.31 & $15,200,000$ & 605 & $87,800,000$ & 7.4 & 0 \\
E88 & 15.02 & $20,700,000$ & 907 & $178,000,000$ & 7.7 & 0 \\
E109 & 19.27 & $20,700,000$ & 561 & $115,000,000$ & 9.2 & 0 \\
E120 & 19.73 & $21,300,000$ & 804 & $180,000,000$ & 5.5 & 0 \\
E128 & 22.03 & $21,900,000$ & 682 & $146,000,000$ & 9.5 & 0 \\
E144 & 22.08 & $20,900,000$ & 713 & $156,000,000$ & 7.3 & 0 \\
E165/P0:1 & 26.59 & $27,600,000$ & 605 & $174,000,000$ & 5.8 & 2.36 \\
E165/P0:2 & 26.80 & $25,600,000$ & 693 & $189,000,000$ & 10.9 & 3.38 \\
E165/P0:3 & 30.55 & $23,800,000$ & 819 & $200,000,000$ & 5.2 & 0.31
\end{tabular}

Mean axon density values at E65 and E72 are equal to the arithmetic mean of 3 EM samples, which encompassed the entire tract at these ages. Mean axon density estimates from E85 through E144 are calculated as described in Materials and Methods. Mean axon density estimates for $\mathrm{P} 0: 1$ and $\mathrm{P} 0: 2$ are equal to the arithmetic mean of axon density estimates from all 10 sectors.

randomly from the 75 th or 90 th section of each series and then micrographs of these fields were taken from all of the sections in the series. The fields were photographed and printed at a final magnification of $15,000 \times$ for analysis. Profiles were color coded and traced through each micrograph to determine their origin (either from axons or glial cells) and to locate their termination within the span of the corpus callosum included in the set of serial sections.

\section{Results}

The number and cytology of callosal axons in the adult

The number of callosal axons and the axon composition of the adult rhesus monkey has been described recently (LaMantia and Rakic, 1990a), and is summarized here to serve as a framework for the present developmental analysis. The corpus callosum in the adult rhesus monkey contains 56 million axons $\pm 6.8 \% \mathrm{SEM}$, with a range of 37 to 70 million $(n=8)$. Subsets of sectors have distinct sizes and proportions of myelinated and unmyelinated axons. Thus, small myelinated axons (diameter $<0.5 \mu$ ) and the largest proportion of unmyelinated axons, $\simeq 20 \%$, are concentrated in sectors 1,2 , and 3 , the 3 most anterior sectors of the corpus callosum (for definitions of the sectors, see Fig. 1; Materials and Methods; and LaMantia and Rakic, 1990). In contrast, sectors 6,7 , and 10 are unique in that they contain very large myelinated axons (diameter $>2.5 \mu \mathrm{m}$ ) dispersed among small-, medium-, and large-sized myelinated axons and the lowest percentage of unmyelinated axons, $\simeq 7 \%$. Finally, sectors $4,5,8$, and 9 may be considered transitional because they contain a mixture of small-, medium-, and large-sized myelinated axons. These differences in axon size and extent of myelination are reflected in axon density in each sector. Thus, the sectors with the smallest axons and the largest proportion of unmyelinated axons (i.e., sectors 1, 2, and 3) have the highest axon density, while those with the largest myelinated axons and fewest unmyelinated axons (i.e., sectors 6, 7, and 10) have the lowest axon density.

\section{Axon addition}

Cytology of the corpus callosum. To obtain reliable estimates of the number of axons in the developing corpus callosum, the borders of the tract must be delineated clearly and the various cellular elements within the tract identified accurately. In the monkey, the corpus callosum is first seen at the midline between $\mathrm{E} 60$ and $\mathrm{E} 65$ as a discrete fusion of the anterior portions of the midsagittal surface of the cerebral hemispheres. Since at these ages only the cortical neurons belonging to layers $\mathrm{V}$ and VI have been generated (Rakic, 1982), the earliest callosal axons must originate from the infragranular layers. However, at the midsagittal plane these early arriving axons do not differ ultrastructurally from those that arrive later. At all prenatal ages examined, the tract itself is cytologically homogeneous. It consists primarily of tightly packed neuritic and glial elements, most of which run orthogonal to the sagittal plane. The dorsal border of the tract is adjacent to the hippocampal primordium, which at earliest ages lies in an anterodorsal location (Rakic and Yakovlev, 1968). At these ages the hippocampal primordium is composed of tightly packed cells with large euchromatic nuclei, a single prominent nucleolus and a thin ring of cytoplasm (Fig. $2, A, B)$. The ventral border of the tract is continuous with the septum pellucidum, which, in the fetus, consists of large cell bodies with prominent stacks of rough endoplasmic reticulum, lysosomes, and vacuoles (Fig. 2, $A, C$ ), as well as numerous cell processes oriented in several directions (Fig. 2, $A, C$ ). The presence of the cytologically distinct hippocampal primordium and septum pellucidum makes it possible to define clearly the boundaries of the corpus callosum in fetal tissue at both the light and electron microscopic levels.

Axons. During the period of axon addition, all callosal axons are unmyelinated (Table 1), and their size is below the resolution of the light microscope. Electron microscopic observation shows that they are oriented predominantly orthogonally to the midsagittal plane. The axons have regularly arranged microtubules and neurofilaments within a light granular cytoplasmic matrix (Fig. 2B; see also Figs. 5, 8, 9). Between E65 and E128 the diameters of callosal axons are distributed unimodally around a mean of approximately $0.25 \mu \mathrm{m}$ (Fig. 3). However, at later fetal ages the range of axon diameters increases and a slight "shoulder" appears at the larger end of the distribution (Fig. 3). This distribution of axon diameters may reflect a continuum that begins with smaller axons whose growing tips have already passed the midline and ends with the larger "wrists" of growing axons just before they expand into growth cones (see Figs. 7, 8). 

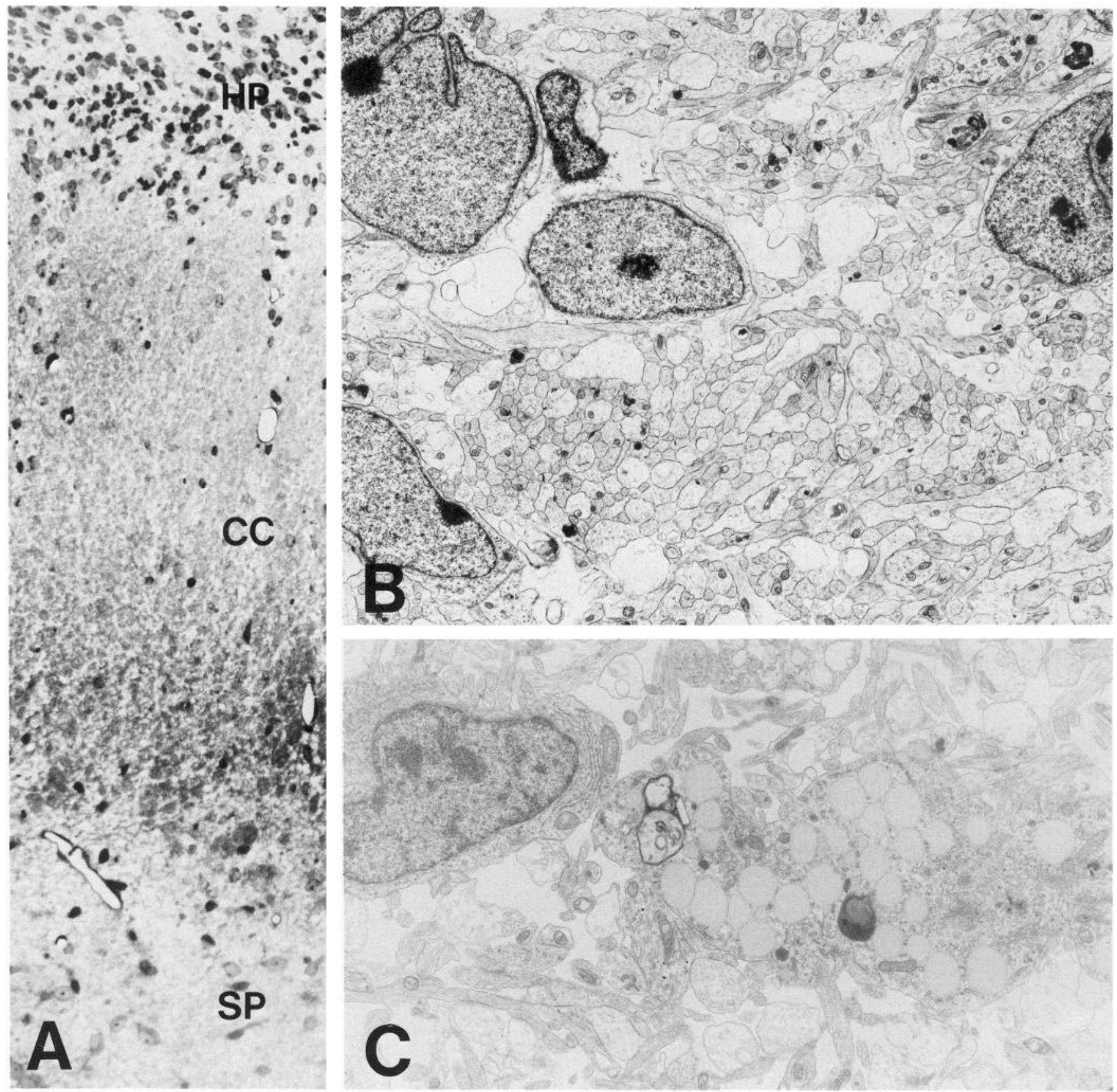

Figure 2. A, Light micrograph of dorsal (top) to ventral extent of the midsagittal corpus callosum (CC) at E65. The darkly stained cells in the dorsal region belong to the hippocampal primordium $(H P)$. The loose, reticular zone with larger, more pale cells in the ventral region constitutes the septum pellucidum $(S P)$. Magnification $120 \times . B$. Electron micrograph of neuroepithelial cells (top $1 / 3$ of micrograph) in the hippocampal primordium at its border with the developing corpus callosum. Magnification $4000 \times$. C, Electron micrograph of large pale cells in the septum pellucidum with prominent stacks of rough ER and numerous electron dense inclusions. Magnification $5500 \times$.

During prenatal development, variation in axon density in the different sectors of the corpus callosum is relatively small. For example, at E88 and thereafter sectors 4 and 6 tend to have slightly lower axon density compared to sectors 2,8 , and 10 . In older fetuses, sector 10 displays the highest axon density. Regional differences become more pronounced in newborn animals and are maintained throughout the period of postnatal axon elimination (see below). Small differences in axon density seen in specimens near term may be due to higher, seemingly random, local concentrations of axons which are occasionally found throughout the tract as well as asynchrony of glial differentiation in sectors where myelination begins earlier.

Glial cells. Non-neuronal cells and their processes are present in the corpus callosum from the earliest time the tract appears at the midline. If not identified, these elements could cause errors in the axon number estimates. We found that immature glial cells are characterized by electron-lucent, organelle-rich cytoplasm with occasional cisternae of rough endoplasmic reticulum, free ribosomes, and randomly distributed intermediate filaments (Fig. $4 A$ ). Their processes contain cisternae of rough 


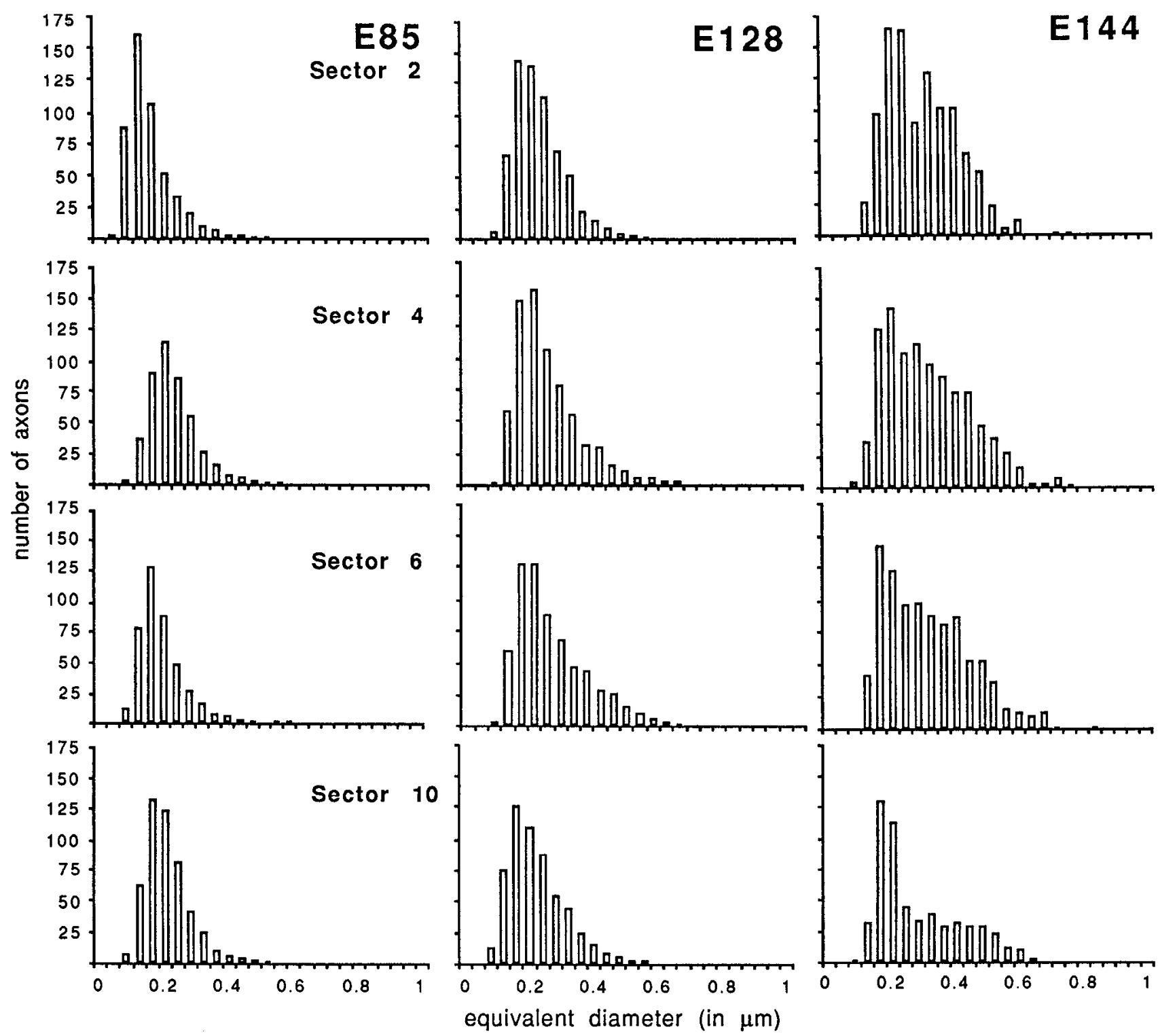

Figure 3. Axon size histograms from sectors 2, 4, 6, and 10 of the corpus callosum at E85, E128, and E144.

endoplasmic reticulum, numerous free ribosomes, ribosome rosettes, and occasional intermediate filaments in an electronlucent, fine granular matrix (Fig. 4B). By E88 at least two morphologically distinct classes of glial cells can be recognized. The first type of glia has electron-lucent cytoplasm, endoplasmic reticulum, Golgi cisternae, numerous mitochondria, and large vacuoles (Fig. $5 A$ ), and may give rise to the numerous round profiles with light granular cytoplasm shown in Figure 5. However, the lack of ribosomes and other characteristic organelles within these profiles does not permit their definitive identification as glial or neuronal processes in single sections. The second type has dark, organelle-rich cytoplasm (Fig. $5 B$ ), and may give rise to the small, round, dark profiles encountered in the prenatal corpus callosum (see Figs. 7, 8).

Growth cones. We have observed 2 distinct classes of profiles that have several well established hallmarks of axonal growth cones. These profiles are either round or lamellate in their shape. The absence of ribosomes, rough endoplasmic reticulum, and other organelles in these profiles suggests that they are axonal rather than glial processes (compare Figs. $4 B$ and $6, A, B$ ). However, the analysis of electron micrographs prepared from single sections cannot exclude the possibility that some of these processes originate from glial cells with light, organelle-sparse cytoplasm (e.g., Figs. 4, 5A).

Reconstruction of representatives from each class of process through 150-180 serial sections demonstrates that both the round (Fig. 7) and lamellate processes (Fig. 8) can be traced back to axons in one direction and to a blunt termination at the other end of the series. None of these reconstructed processes were continuous with glial cell bodies or with processes containing ribosomes and intermediate filaments. The ultrastructural composition of the round profiles varied randomly throughout the length of the process. At some levels they may contain vesicles, at others they may contain arrays of microtubules. The branched lamellate processes usually have a core of microtubules and neurofilaments at the intersection point of the arms. The branches themselves, as well as individual rod-shaped processes, have a simpler internal morphology with a light, granular cytoplasmic 


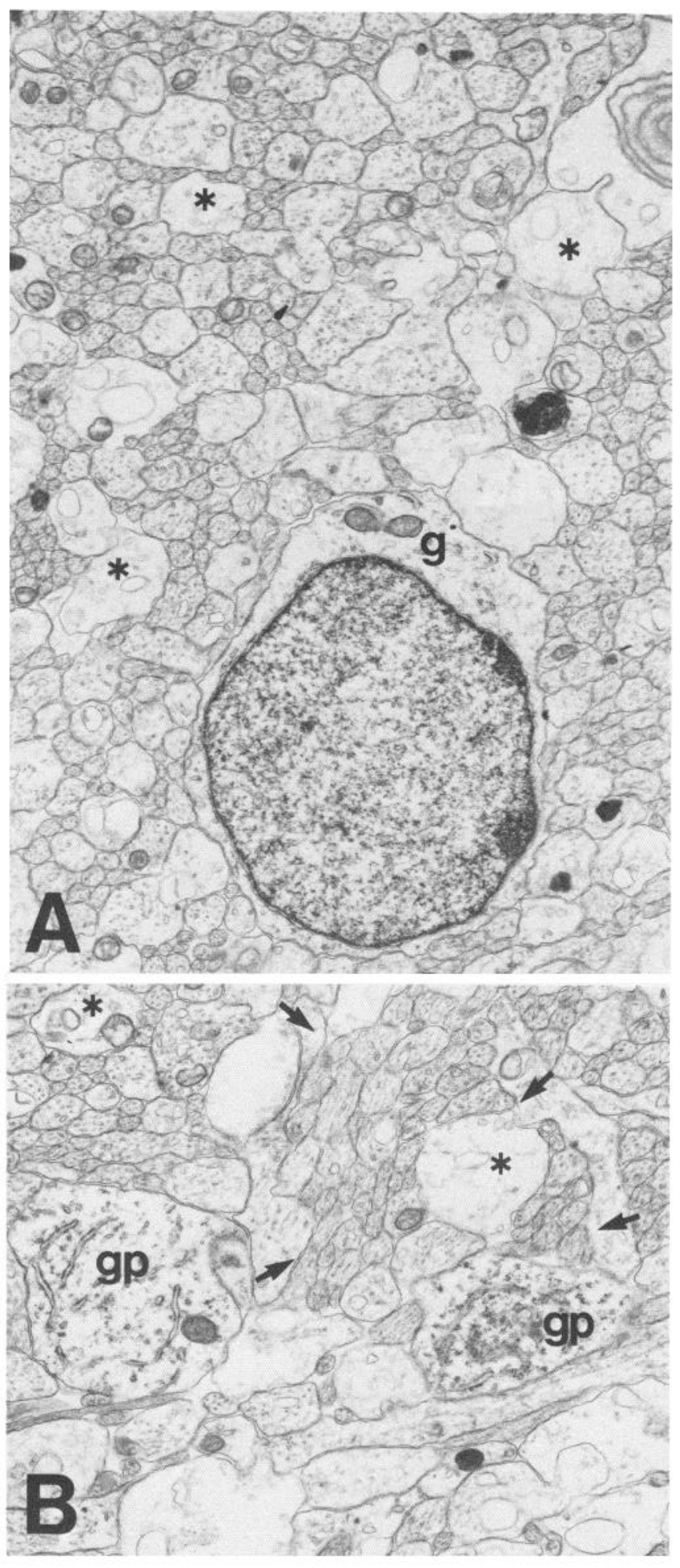

Figure 4. Electron micrographs of the corpus callosum at E65, shortly after axons initially penetrate the midline. $A$, An undifferentiated glial cell $(g)$ is situated within a field of densely packed axons of varying sizes and other larger profiles. Asterisks denote larger, polymorphic processes containing intermediate filaments, microtubules, and granular cytoplasm. Magnification $9200 \times, B$, A slightly higher power micrograph showing lamellate profiles (arrows) and round profiles (asterisks), and glial processes $(g p)$ which contain dark mitochondria, regularly arrayed ER, free ribosomes, and ribosome rosettes. Magnification 10,000×.
Table 2. Changes in the numbers of growth cones and proportion of growth cones to axons during the phase of net axon addition

\begin{tabular}{llrlr} 
Age & $\begin{array}{l}\text { GC } \\
\text { density/ } \\
100 \mu \mathrm{m}^{2}\end{array}$ & $\mathrm{nGc}$ & $\begin{array}{l}\text { nGc/ } \\
n \text { axons }\end{array}$ & $\begin{array}{l}\text { nGC }+ \\
n \text { axons }\end{array}$ \\
\hline E65 & 17.1 & 205,000 & 0.051 & $4,215,000$ \\
E72 & 14.3 & 213,000 & 0.032 & $6,983,000$ \\
E85 & 23.0 & $3,510,000$ & 0.040 & $91,300,000$ \\
E88 & 35.5 & $7,810,000$ & 0.044 & $186,000,000$ \\
E109 & 23.2 & $4,870,000$ & 0.042 & $120,000,000$ \\
E120 & 31.2 & $8,000,000$ & 0.044 & $188,000,000$ \\
E128 & 19.4 & $5,550,000$ & 0.038 & $173,000,000$ \\
E144 & 3.7 & 630,000 & 0.004 & $152,000,000$ \\
E165/P0:1 & 0.0 & 0 & 0.000 & $188,000,000$ \\
E165/P0:2 & 0.0 & 0 & 0.000 & $174,000,000$ \\
E165/P0:3 & 0.0 & 0 & 0.000 & $200,000,000$
\end{tabular}

Growth cone density and number estimates reflect both lamellate and round growth cones observed at the midline. The growth cone density values shown here were determined from the same micrographs used to estimate axon density (see Table 1).

matrix and occasional accumulations of vesicles. Although the morphology of the round and lamellate profiles is distinct, these two types of growth cones have been scored generically as "growth cones" in our quantitative analysis, since some round profiles encountered in a single section may be "wrists" of growing axons that will eventually open into a lamellate ending (e.g., Fig. 8, s12). Between E65 and E145 both the round and lamellate profiles are distributed randomly throughout the developing corpus callosum. Neither type appears to be apposed consistently to any specific class of cells or processes. Growth cones can be seen next to axons, next to other growth cones (Figs. 6,7), or next to glial cells and processes (Fig. 4, $A, B$ ).

The magnitude and timing of axon addition. The number of axons in the corpus callosum increases from the time the tract appears around embryonic day 65 (E65) until birth (represented here by 3 monkeys delivered by caesarian section on E165) when it contains 188 million axons (Table 1, Fig. 9). The increase in axon number is somewhat linear $\left(\tau^{2}=0.653\right)$. There is, however, a fair amount of variability in the number of callosal axons in the 11 fetal and newborn monkeys analyzed in this study. In particular, the number of callosal axons found in the monkeys at E88 (178 million) and E120 (180 million) approximate the apparent maximum found at birth (188 million, $n=3$, range $=174-200$ million). Whether or not this represents normal variability or concomitant addition and elimination of axons cannot be determined. Nevertheless, the overall trend toward an increase in the number of axons in the corpus callosum from the time it appears around E65 through birth implies that there is a primarily progressive addition to axons during this time.

This conclusion is reinforced by examining the presence and number of growth cones in the corpus callosum. First, although growth cones are seen throughout the callosum from E65 through E145 (the period of net increase of callosal axons), growth cone profiles (identified using criteria established in the serial reconstructions) are never seen at birth or afterward. Second, the apparent peak of 188 million axons at birth represents the highest number of neurites (axons and growth cones; Table 2) ever seen in the corpus callosum. Third, the proportion of growth cones during most of the period of net axon addition remains 

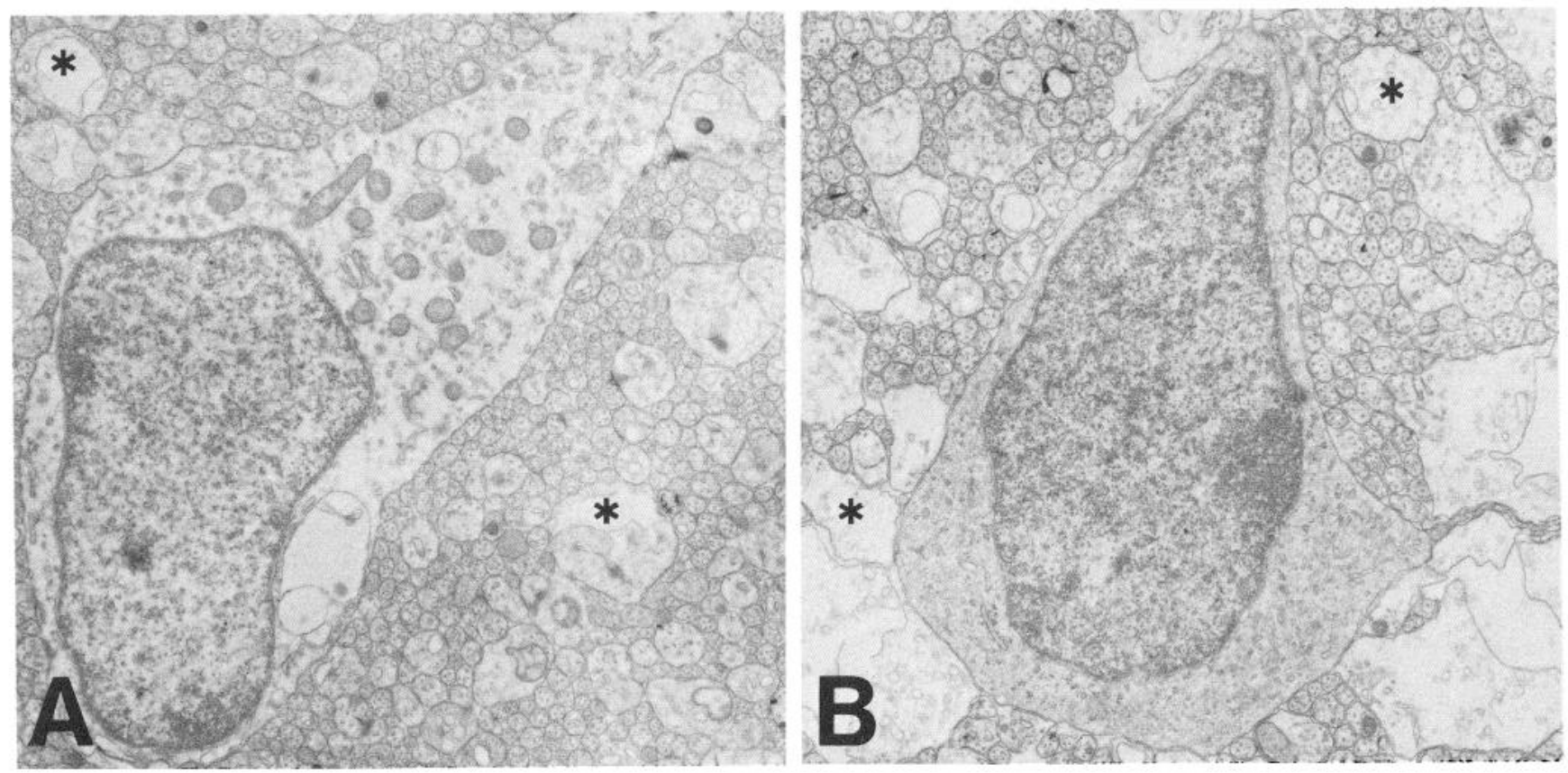

Figure 5. Two distinct classes of glial cells in the corpus callosum of an E120 rhesus monkey fetus. $A$, This cell has electron-lucent organelle-rich cytoplasm characterized by numerous pale mitochondria, rough ER, free ribosomes, Golgi cisternae, and membranous inclusions. The round profiles (asterisks in $A$ and $B$ ) may originate from glial cells similar to this one. Magnification $10,000 \times . B$, Cell with electron dense cytoplasm, numerous free ribosomes, ribosome rosettes, smooth ER, vesicles, and occasional rough ER cisternae. Magnification 12,000×.

constant at approximately 4 growth cones to every 100 axons. This proportion apparently declines by the last 3 weeks of gestation. This implies that there is constant addition of axons during gestation. The question of whether or not the net increase represents a progressive increase is difficult to answer definitely. A simple average rate of addition of approximately 2 million axons/d is needed to achieve the maximum number of axons. Clearly, the number of growth cones observed during most of the period of axon addition approximates this value. However, it is not possible to determine whether the addition of axons due to these growth cones may be offset by some retraction of axons; unfortunately, ultrastructural evidence of retracting ax-
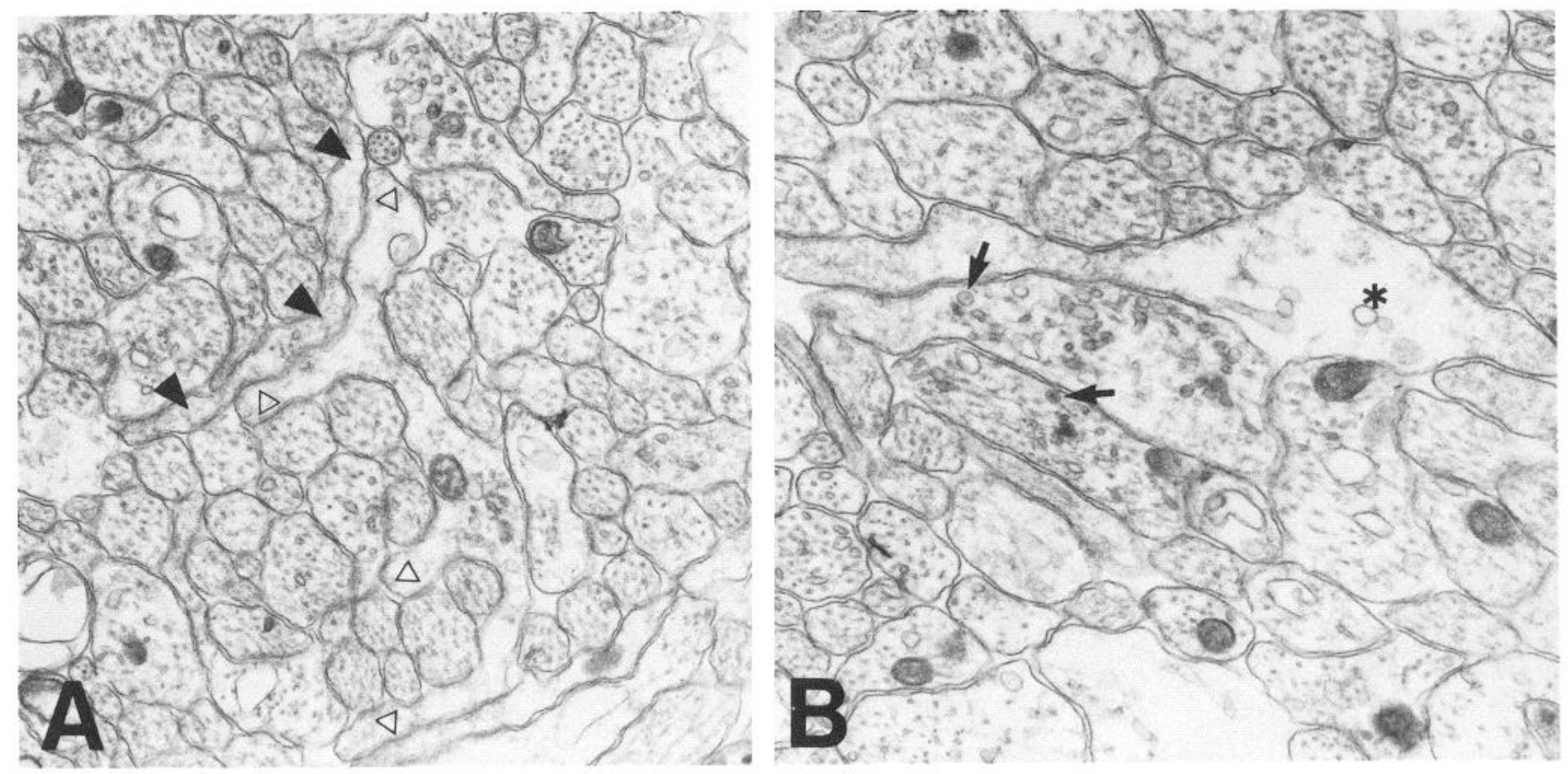

Figure 6. Lamellate processes in the corpus callosum at E65. A, The processes can either be sheet-like (solid arrowheads) or have several radial arms (open arrowheads). These processes often are apposed to one another, and in the areas of apposition there is often an accumulation of fibrous material (open arrowheads). Magnification $18,000 \times . B$. Higher power micrograph of 2 lamellate processes apposed to one another. The processes often have electron lucent as well as dense core vesicles (arrows). Magnification 23,000×. 

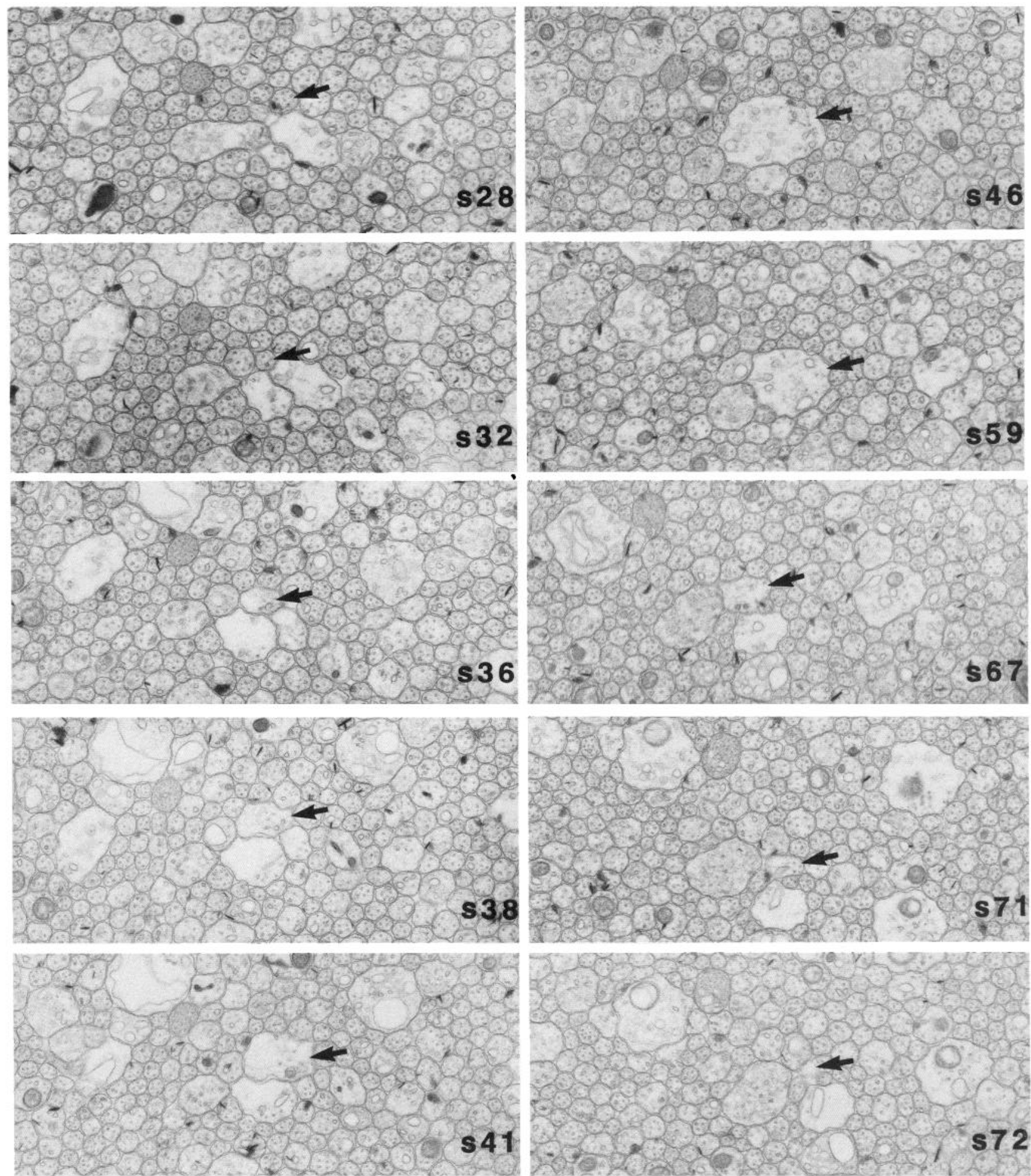

Figure 7. Representative sections showing a round axon process (arrow) reconstructed from 44 serial sections from the corpus callosum of an E88 monkey fetus. This process begins as an axon similar in size and morphology to surrounding axons in section 28 (s28). Before opening into a round profile with an electron-lucent, flocculent matrix, the axon seems to lose its regularly spaced array of microtubules. Aside from the light flocculent cytoplasmic matrix present throughout the process there are round and flattened vesicles and a small mitochondrion (s41). In several of the sections the process appears very closely apposed to the axons that surround it $(s 41, s 46, s 59)$, and at no point is there excess extracellular space, which might indicate that the profile was a result of a fixation artifact. Magnification $12,400 \times$. 

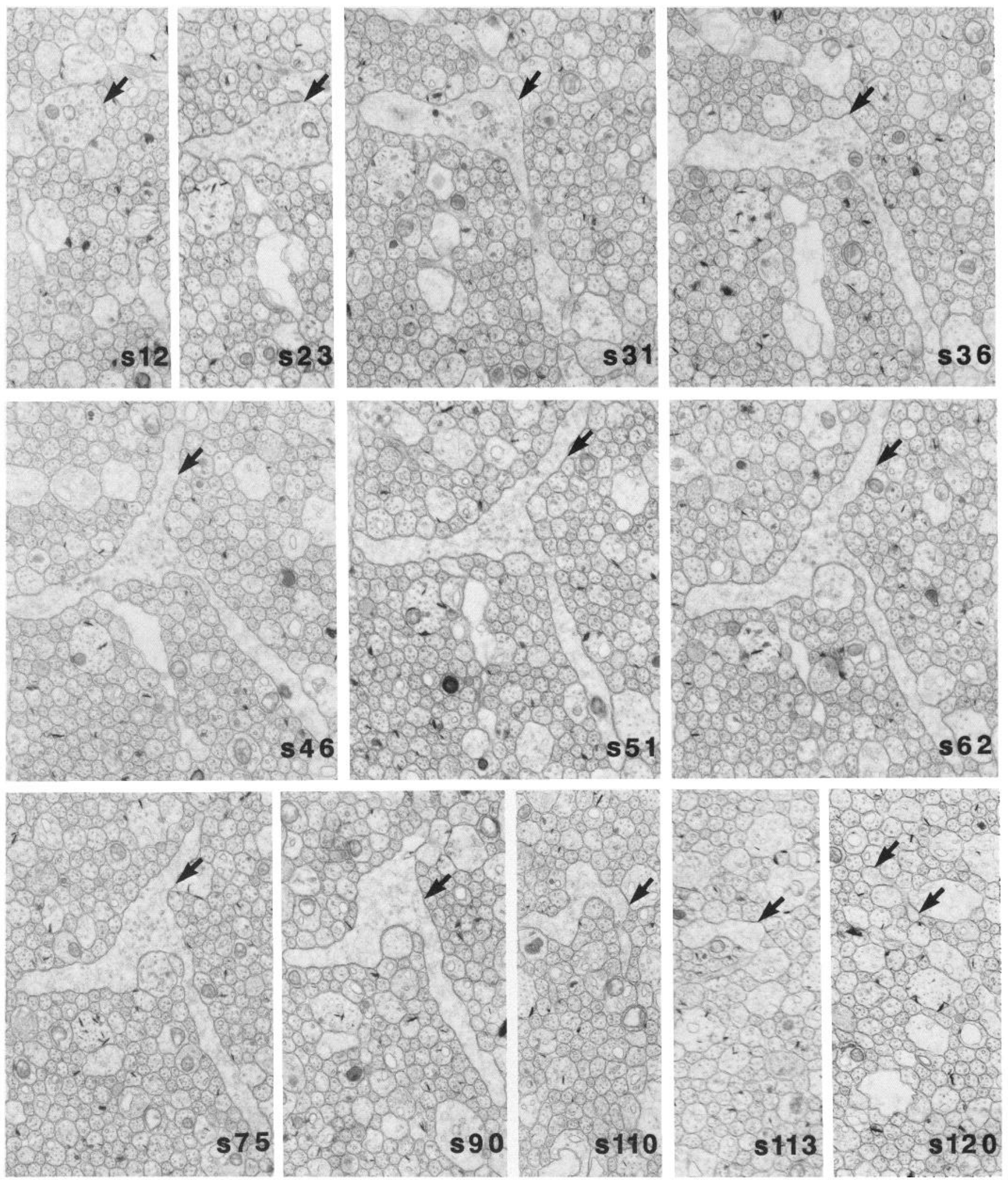

Figure 8. Representative sections showing a lamellate growth cone in the corpus callosum reconstructed from 108 serial sections from the corpus callosum of an E88 monkey fetus. The arrow in each micrograph denotes the growth cone. It begins as a round axonal profile with a small mitochondrion, numerous microtubules, and some smooth vesicles surrounded by a light granular matrix. Further in the series the process acquires 3 radial arms. The cytoplasm of these arms has fewer tubules or filaments than the central core of the process, which maintains a high concentration of microtubules throughout its length. Magnification $12,000 \times$. 


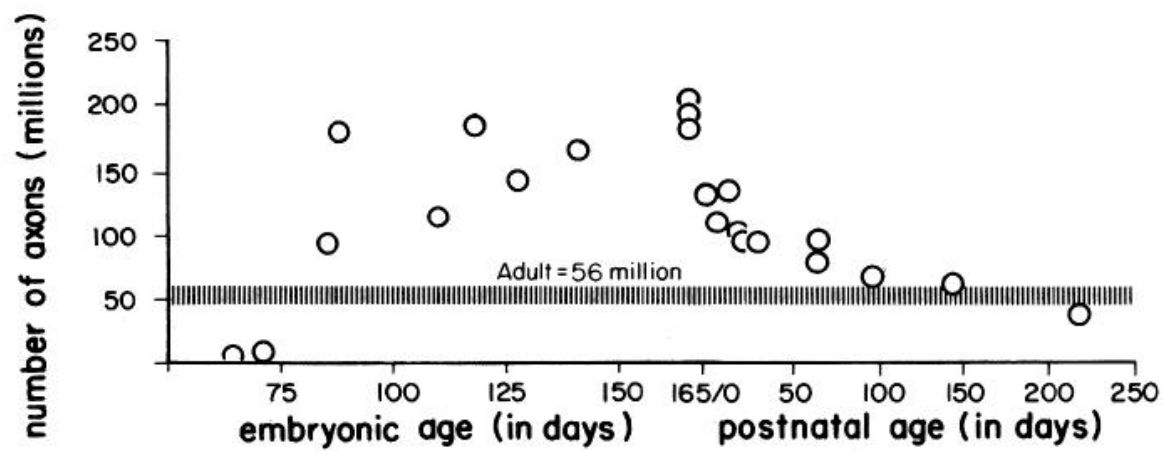

Figure 9. The total number of axons in the corpora callosa of 22 fetal, neonatal, and juvenile rhesus monkeys plotted as a function of postconceptual age in days. The youngest animal examined was E65 (which is shortly after the corpus callosum forms at the midline) and the three animals shown at P0 (day of birth) in this graph are all conceptual age E165 (average day of birth for rhesus monkeys, these animals delivered by caesarian section). Each point represents one animal, and the sample error for each estimate is equal to or less than the size of the dots used to represent each data point of the graph $(<14 \%$, see Tables 1 and 3$)$. The hatched line indicates the number of axons in the adult rhesus monkey corpus callosum (from LaMantia and Rakic, 1990).

ons remains elusive. Although these issues make it difficult to rule out a very complicated process that results in the net addition of axons described here, the available data on changes in the numbers of axons over time, along with that of the numbers of profiles confidently identified as growth cones, suggest that the prenatal development of the corpus callosum is primarily a process of axon addition that reaches a maximum at birth.

\section{Axon elimination}

Cytology of the corpus callosum during axon elimination. A decrease in the number of axons in the corpus callosum can be detected as early as $5 \mathrm{~d}$ after birth, and the number continues to decrease until the 6 th postnatal month. During this period the remaining axons increase in diameter, and become myelinated. In addition, glial cells and processes are more numerous. As a result, the midsagittal surface area of the corpus callosum expands during postnatal axon elimination (Table 3). These general features as well as the significant regional variation in the cytological maturation of the corpus callosum after birth must be considered to ensure accurate estimates of the number of axons in the tract during postnatal development.

Axons. The 2 most notable changes in the cytological composition of the corpus callosum during early postnatal development are the absence of growth cones and the emergence of
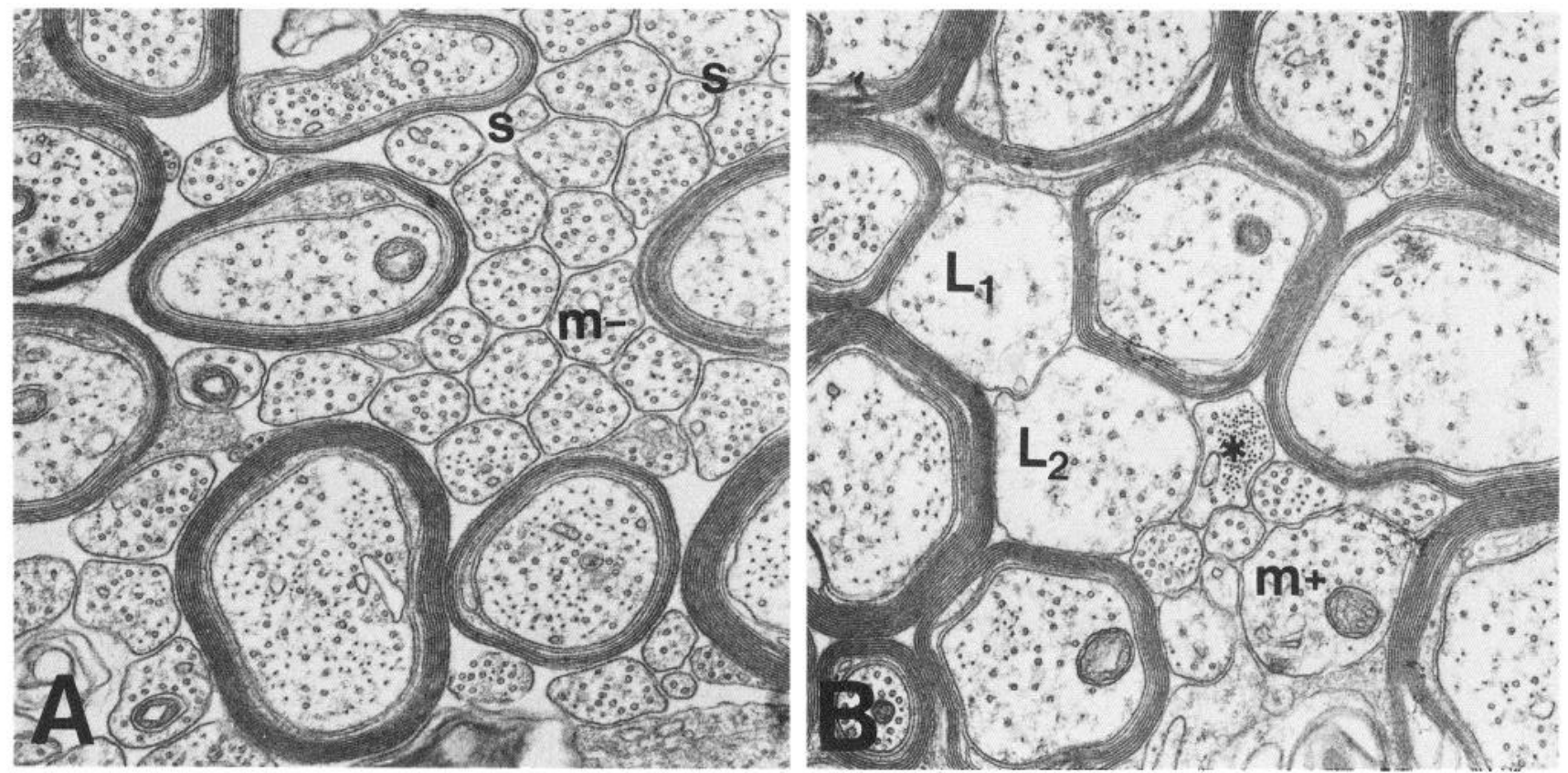

Figure 10. A, The smallest unmyelinated axons $(s$, arrowhead $)$ in sector 4 of the P90 specimen contain only 1 or 2 microtubules and can be as narrow as $0.1 \mu \mathrm{m}$ in diameter. The medium-sized unmyelinated axons range from $0.2 \mu \mathrm{m}(\mathrm{m}-)$ to $0.4 \mu \mathrm{m},(m+$, in $B)$ and have a dense lattice of microtubules and neurofilaments. Magnification $31,000 \times . B$. The largest unmyelinated fibers from the same specimen are at least $0.4 \mu \mathrm{m}$ in diameter, irregularly shaped, and contain either a dense lattice of cytoskeletal elements $\left(L_{l}\right)$ or a somewhat more sparse array of microtubules within a flocculent cytoplasmic matrix $\left(L_{2}\right)$. An asterisk indicates an astrocytic process with a bundle of intermediate filaments. Magnification $31,000 \times$. 

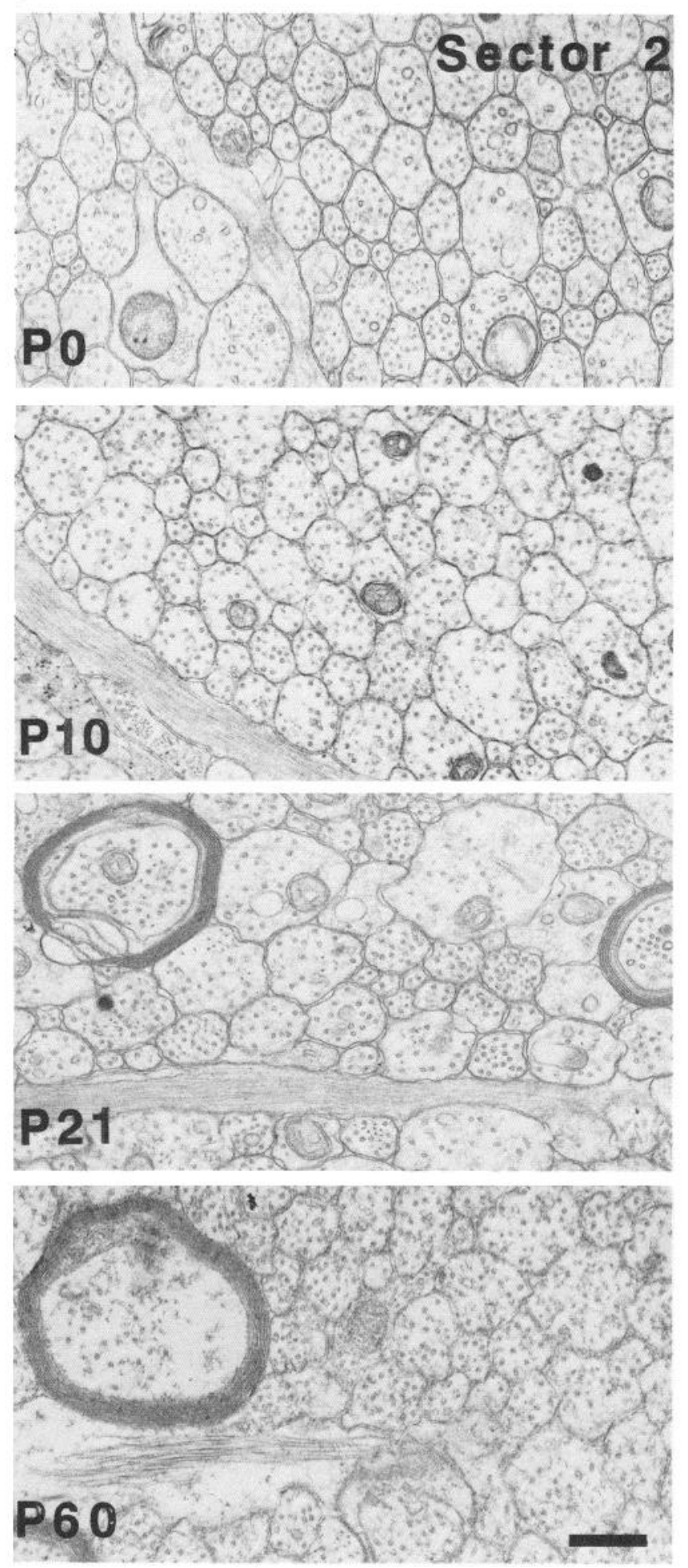
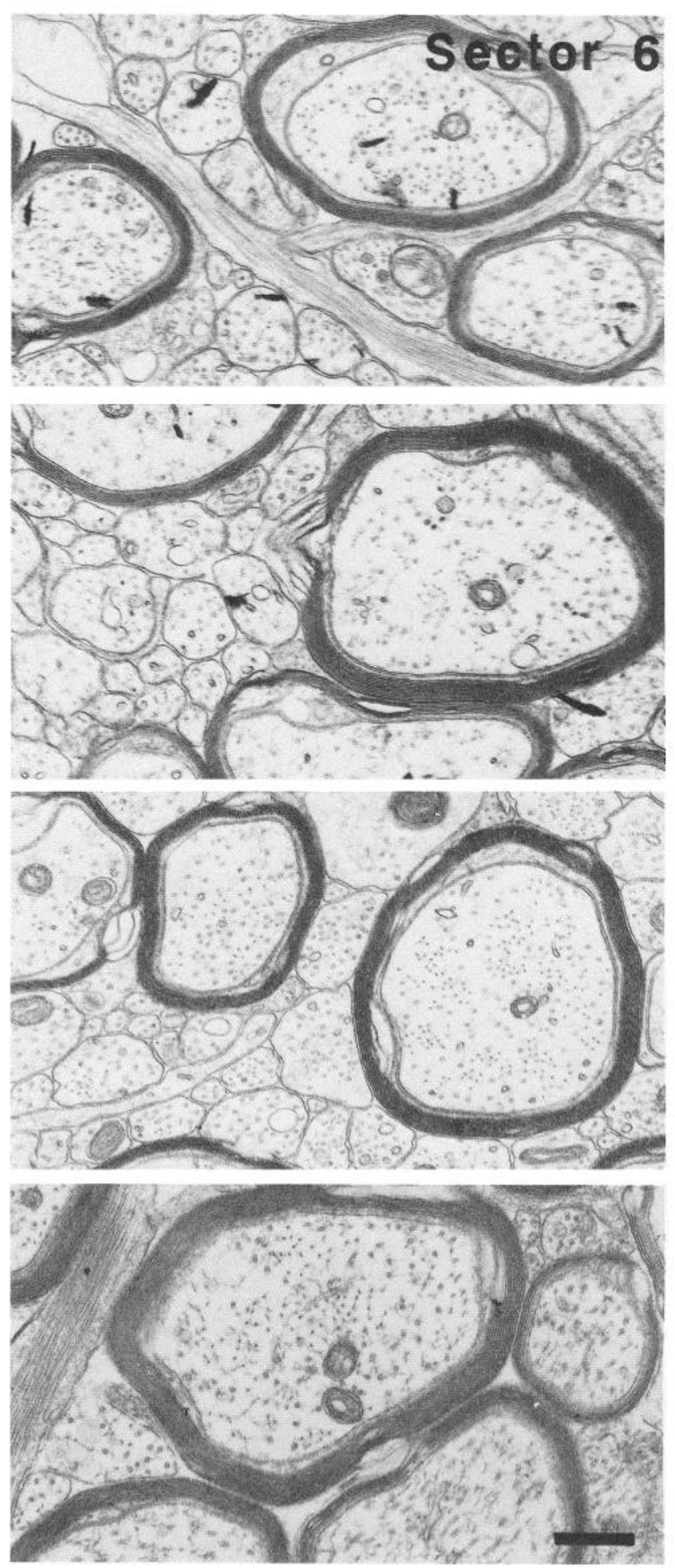

Figure 11. Electron micrographs of sectors 2 and 6 at P0, P10, P21, and P90. All micrographs are shown at the same final magnification. Differences in axon composition between the 2 regions are seen at birth and persist through the period of axon elimination. The size ranges of both unmyelinated and myelinated axons are relatively constant during axon elimination (see also Figs. 12 and 15), and the continuum of axon sizes, as well as apparent differences in density of microtubules within axons, exists throughout the early postnatal period. Magnification $25,000 \times$.

myelinated axons. The measurements of unmyelinated and myelinated axon diameters during this period do not reveal a simple linear relationship between increase in axon diameter and myelination, as suggested for some other axon populations (Friede, 1972). Instead, we found a continuum of sizes and types of myelinated and unmyelinated axons (Figs. 10, 11). At the beginning of the spectrum there are small unmyelinated axons that resemble those seen in the fetal corpus callosum. In the middle of the spectrum there are medium-sized myelinated as well as unmyelinated axons which have numerous microtubules 

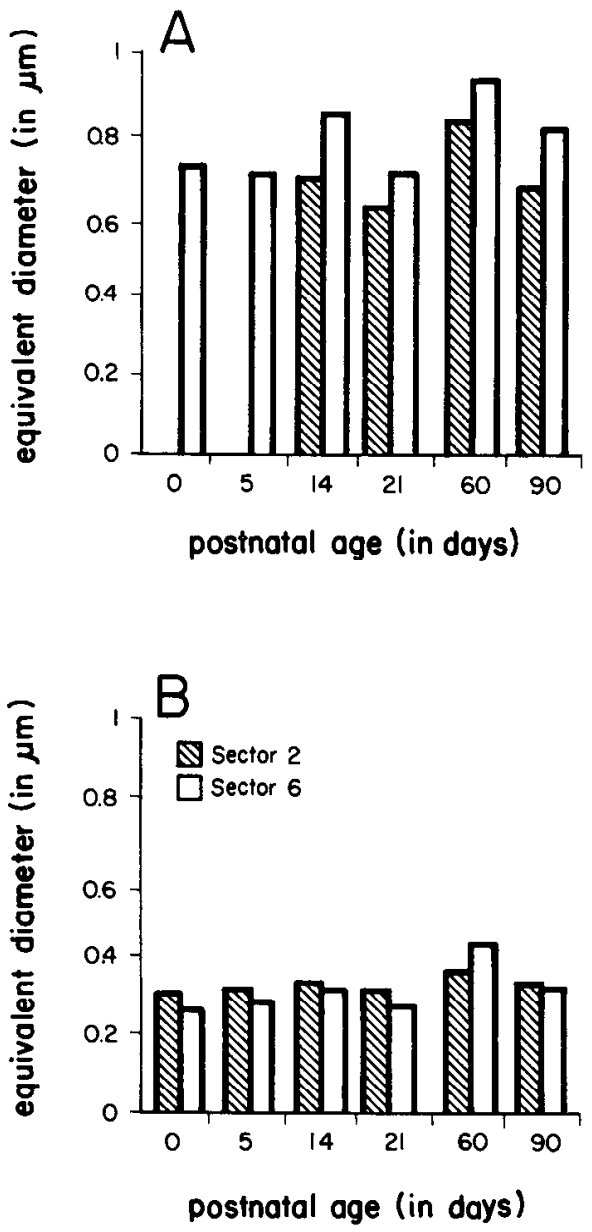

Figure 12. Axon diameter in sectors 2 and 6 from P0 through P90. Axon diameter is expressed as the equivalent diameter: the diameter of a true circle with the area of the axon measured. The mean diameter of the myelinated $(A)$ and unmyelinated $(B)$ axon populations are relatively consistent from age to age. Thus, as a population, the diameters of callosal axons do not increase linearly as the axons become myelinated. The mean diameter of myelinated axons in sector 2 is consistently lower than that for sector 6 from birth onward. and neurofilaments. At the end of the spectrum there are large, slightly irregularly shaped myelinated and unmyelinated axons with fewer microtubules, filaments, and vesicles.

Because of the differences in axon size and myelination that emerge after birth, distinct callosal sectors can be defined with the geometrical strategy used for analyzing the adult callosum (Fig. 1; LaMantia and Rakic, 1990). Throughout the period of axon elimination, axon density is lowest in sector 6 and highest in sector 2 (Fig. 11; see also Table 4). The identity of these sectors is also reflected in the mean diameter of myelinated axons, which is always larger in sector 6 than in sector 2 (Fig. $12 \mathrm{~A}$ ), and in the degree of myelination, which is most advanced in sector 6 and least advanced in sector 2 (Fig. 13). The most notable feature of sectors 6 and 7 is the unique presence of very large myelinated axons $(2-3 \mu)$. The diameters of these axons are at least 5 times larger than the surrounding unmyelinated axons (Fig. 11).

The tempo of axon maturation after birth varies between subsets of sectors, particularly in the extent of myelination (Fig. 13). During the first 2 postnatal months, the axons of sectors 6 and 7 mature most rapidly, while those in the "transitional" sectors $4,5,8$, and 9 mature at an intermediate rate. Thereafter the axons of the transitional sectors myelinate and increase in diamcter at a rate similar to that of sectors 6 and 7 . In contrast, the axons of sectors 1,2 , and 3 take the longest to attain their adult size and morphology. They begin to myelinate approximately 1 month after birth, and myelination continues throughout the 1st postnatal year; however, the proportion of medullated axons in sectors 1, 2, and 3 never reaches that seen in the other sectors. Surprisingly, during the first 3 postnatal months sector 10 resembles sectors 1 through 3 since it has a smaller fraction of myelinated axons (Fig. 13; see also Table 4). However, by the fifth postnatal month, and in the adult, axon density and the degree of myelination in sector 10 resemble that in sectors 6 and 7 .

Glial cells. In postnatal animals, non-neuronal cells and processes in the corpus callosum are more differentiated than before birth, and 2 types of glial cells can be easily distinguished. The first type has a thin ring of electron-lucent perinuclear cytoplasm
Figure 13. Differences in rate of myelination between sectors $2,4,6$, and 10 . Note that when myelination begins in sector 2 (approximately at the end of the first postnatal month) at least $30 \%$ of the axons in sector 6 are myelinated. The adult proportion of myelinated axons for each sector is reached long after axon elimination has been completed.

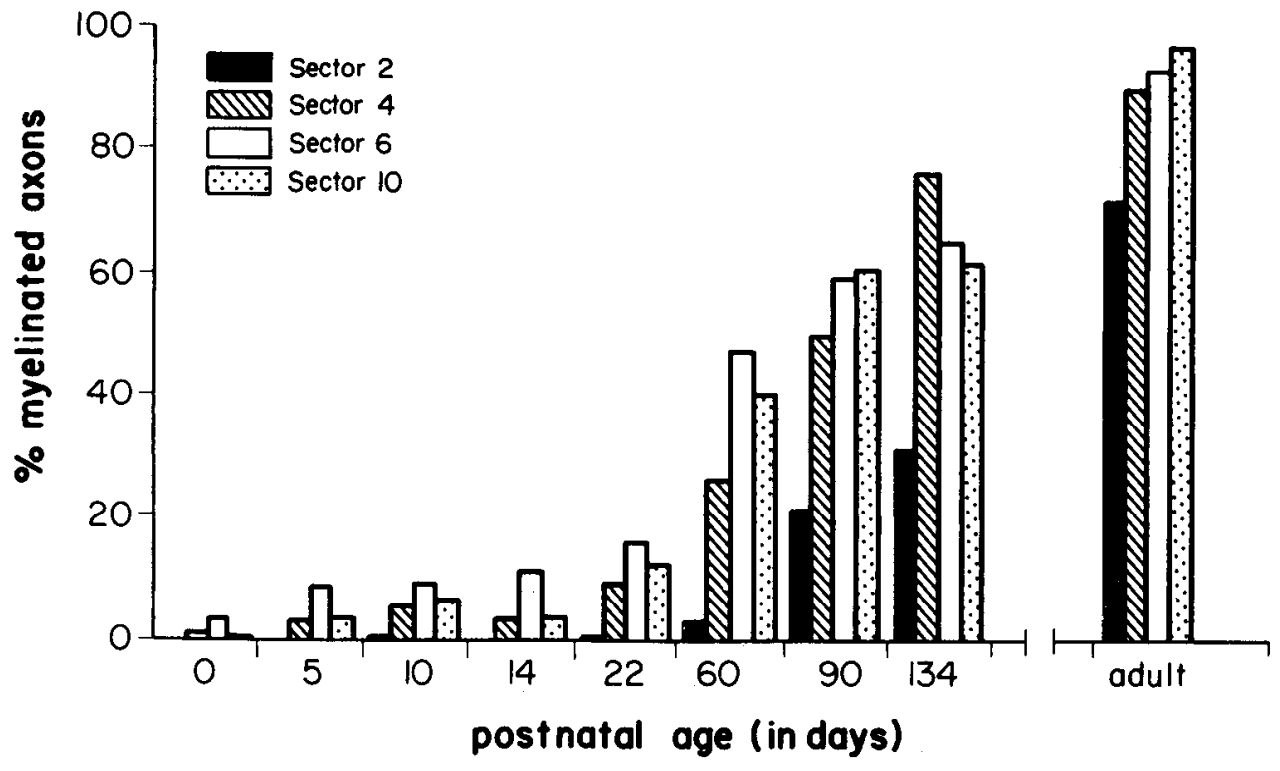



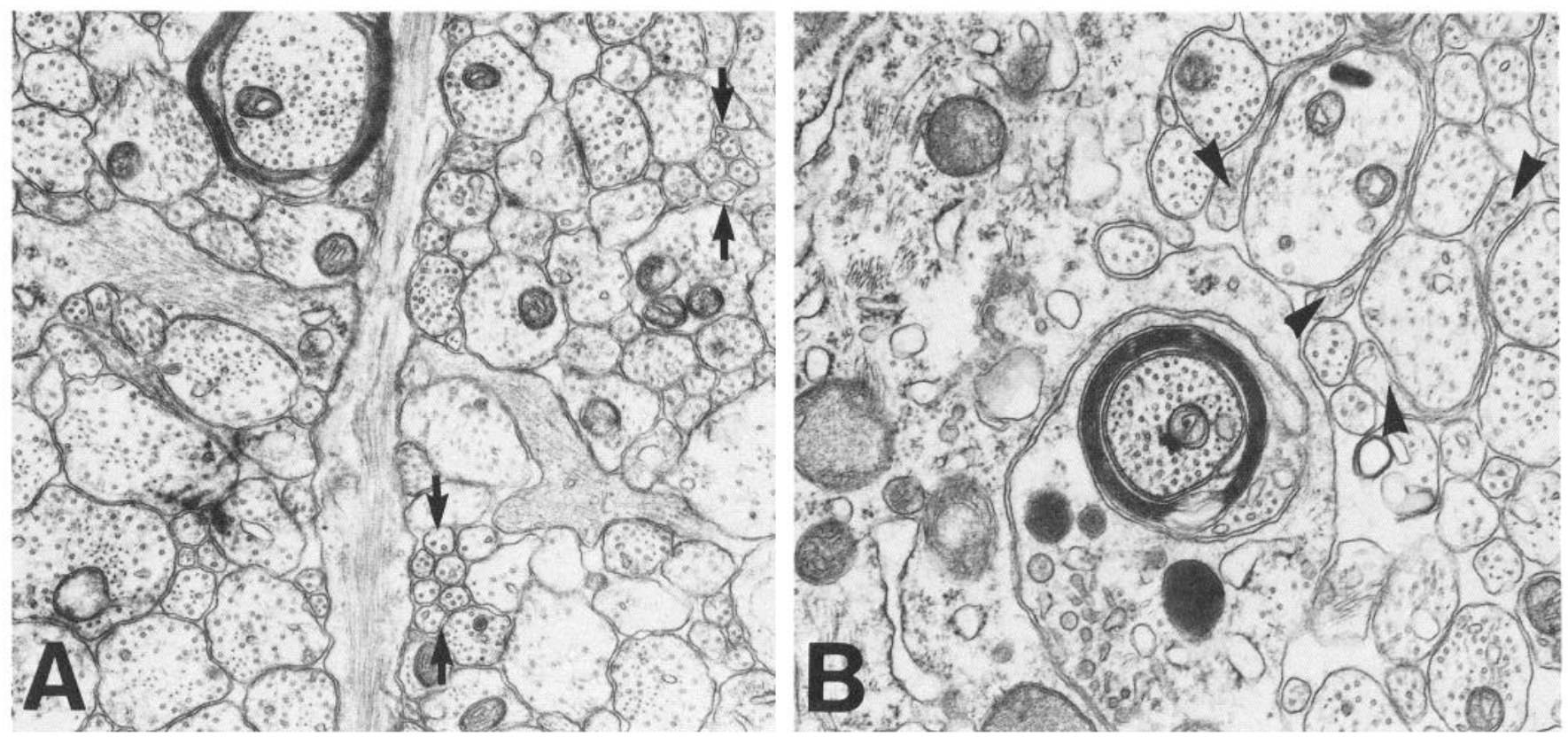

Figure 14. Astrocytic processes in the corpus callosum at birth. A, Two astrocytic processes intersecting in the midsagittal plane of the corpus callosum at P0. Both processes contain dense bundles of intermediate filaments. A glial growth cone, filled with pleiomorphic vesicles, and originating from a process filled with dense braids of intermediate filaments, can be seen at the right of the micrograph. There are small unmyelinated axons with numerous microtubules and neurofilaments (arrows), large myelinated axons, large unmyelinated axons with numerous microtubules and neurofilaments, and large unmyelinated axons with organelle-sparse cytoplasm. Magnification $26,000 \times$. B, A process with light cytoplasm and occasional bundles of intermediate filaments is seen enveloping an already myelinated axon, and appears to be continuous with the myelin lamellae. Arrowheads indicate examples of small oligodendroglial processes which resemble small unmyelinated axons. Magnification $30,000 \times$.

filled with mitochondria, rough endoplasmic reticulum, prominent Golgi cisternae, and dense bundles of intermediate filaments. The elongated processes of these cells are filled with longitudinally oriented bundles of intermediate filaments, and often terminate in vesicle-filled profiles (Fig. 14A). Some glial processes are oriented orthogonally to the midsagittal plane and appear similar in size and shape to small unmyelinated axons in cross section. Closely packed bundles of intermediate filaments identify these profiles as astrocytic rather than neuronal in origin (e.g., Fig. 10B).

The second type of glial cell contains dark, granular, organellerich cytoplasm characteristic of medium to dark oligodendroglia (Mori and Leblond, 1970). These cells give rise to round and pleomorphic processes with dark granular cytoplasm, occasional microtubules, and few, if any, intermediate filaments. The ultrastructure of the slender processes that envelop myelinating axons usually resembles that of the dark glia. However, some cells have processes with light cytoplasm and intermediate filaments that envelop myelinated axons during this period (Fig. $14 B$ ). One also encounters round to ovoid profiles, with electron-dense cytoplasm that identifies them as oligodendroglial processes (Fig. 14B). These ultrastructural features of glial cells and their processes make it possible to distinguish glial processes from callosal axons and therefore ensure an accurate estimate of axon number.

The magnitude and timing of axon elimination. At birth, approximately 188 million callosal axons $(n=3)$ cross the midline. In the adult this number is 56 million $(n=8$; see also LaMantia and Rakic, 1990). Therefore, over 130 million axons are eliminated from the corpus callosum between birth and adulthood. Our data indicate that these axons are eliminated in
2 phases: the first, rapid phase of axon elimination occurs within the first month after birth, and the second, slow phase continues from the second through sixth postnatal month. During the rapid phase the number of axons drops from 188 million to 110 million (Fig. 9, Table 3). This decrease, though precipitous, appears to be linear $\left(r^{2}=0.719, n=9\right.$, animals from P0 to P21 included), and proceeds at an average rate of approximately 50 axons $/ \mathrm{sec}$. The second phase is considerably slower; axons are eliminated at an average rate of $5 / \mathrm{sec}, 10$ times slower than that during the "rapid" phase. Axon elimination during the slow phase also appears to be linear $\left(r^{2}=0.923, n=7\right.$, animals from P21 to P222 included). Although this second phase appears less dramatic, 48 million axons are eliminated from the corpus callosum during this time; almost as many as will remain in the adult. The adult number of callosal axons is reached between the fourth and fifth postnatal months.

The midsagittal area of the corpus callosum increases during the period of axon elimination from $25 \mathrm{~mm}^{2}$ to $55 \mathrm{~mm}^{2}$, and continues to increase until axon growth and myelination are complete-around 2.5-3 years of age. Growth and myelination of axons and the differentiation of glial cells and their processes causes an increase in the midsagittal area of the corpus callosum that overrides the negative effects of axon elimination (Table 3 ). There is a fair amount of variability, which may be due to the size or sex of the animal. Unfortunately, a much larger sample would be needed to determine the role of these factors. The proportion of myelinated axons throughout the tract does not begin to increase rapidly until P21 (Fig. 13, Table 3). The estimated number of myelinated axons between P0 and P135 never exceeds the total number of axons in the adult (Table 3), and in our electron micrographs we did not observe profiles of 
Table 3. Quantitative characteristics of the CC during postnatal maturation

\begin{tabular}{|c|c|c|c|c|c|c|c|}
\hline Age & $\begin{array}{l}\text { CC length } \\
(\mathrm{mm})\end{array}$ & $\mathrm{CC}$ area & $\begin{array}{l}\text { Axons/ } \\
100 \mu^{2}\end{array}$ & $n$ axons & $\begin{array}{l}\text { Error } \\
(\%)\end{array}$ & $\begin{array}{l}\text { Mean } \\
\text { myelinated } \\
(\%)\end{array}$ & $\begin{array}{l}n \text { myelinated } \\
\text { axons }\end{array}$ \\
\hline $\mathrm{PO}$ & 26.80 & $27,600,000$ & 605 & $174,000,000$ & 10.9 & 3.4 & $5,880,000$ \\
\hline P0 & 26.59 & $25,600,000$ & 693 & $189,000,000$ & 5.8 & 2.4 & $4,460,000$ \\
\hline P0 & 30.55 & $23,800,000$ & 819 & $200,000,000$ & 5.2 & 0.3 & 620,000 \\
\hline P5 & 26.08 & $25,800,000$ & 494 & $131,000,000$ & 7.0 & 5.3 & $6,960,000$ \\
\hline P8 & 27.49 & $35,500,000$ & 318 & $115,000,000$ & 13.8 & 5.9 & $6,770,000$ \\
\hline $\mathrm{P} 10$ & 28.05 & $34,200,000$ & 357 & $133,000,000$ & 7.5 & 7.1 & $9,500,000$ \\
\hline P14 & 26.38 & $26,200,000$ & 376 & $113,000,000$ & 9.1 & 3.5 & $3,930,000$ \\
\hline P21 & 25.47 & $30,300,000$ & 333 & $113,000,000$ & 7.9 & 8.6 & $9,670,000$ \\
\hline P22 & 25.44 & $26,500,000$ & 364 & $108,000,000$ & 7.0 & 11.0 & $11,920,000$ \\
\hline P60 & 34.36 & $43,500,000$ & 192 & $94,700,000$ & 7.4 & 29.2 & $27,650,000$ \\
\hline P60 & 29.09 & $49,700,000$ & 177 & $97,600,000$ & 10.1 & 33.2 & $32,400,000$ \\
\hline P90 & 25.79 & $41,500,000$ & 140 & $66,800,000$ & 6.6 & 48.0 & $32,060,000$ \\
\hline P134 & 29.46 & $55,500,000$ & 102 & $61,900,000$ & 5.2 & 61.2 & $37,880,000$ \\
\hline P222 & 37.03 & $53,400,000$ & 74 & $40,000,000$ & 5.7 & 74.6 & $29,840,000$ \\
\hline
\end{tabular}

Axon number estimates for the 3 P0 animals are based on samples from all 10 sectors. All other estimates are based on samples from sectors $2,4,6,8$, and 10 . The mean percentage of myelinated axons is the arithmetic mean of the percentage of myelinated axons in all sectors analyzed.

degenerating myelinated axons during the period of axon elimination. Therefore, elimination of most, if not all, axons from the corpus callosum occurs before they become myelinated.

The range in diameter of unmyelinated axons between and within the 10 sampling sectors during the period of rapid axon elimination is broad (Fig. 15). The major population of unmyelinated axons, which predominates from birth through P21, has small diameters distributed around a mean of approximately $0.15 \mu \mathrm{m}$. There is a peak around $0.15 \mu \mathrm{m}$ and a shoulder that stretches across the rest of the distribution, through $0.6 \mu \mathrm{m}$. The distribution of axon diameters is more regular in the anterior sectors, which acquire myelin at the slowest rate. These sectors will eventually contain axons with the smallest diameters. In the posterior sectors there is a slight indication of a bimodal distribution of axon diameters. By P60 the predominance of the smallest unmyelinated axons, which constitute the first mode, has diminished, and in the P90 specimen this population cannot be detected in appreciable numbers in any sector except sector 10. Between P60 and P90 the remaining unmyelinated axons in sectors 2 through 8 are distributed more broadly around a mean of approximately $0.4 \mu \mathrm{m}$. As myelination is completed, the larger $(>0.5 \mu \mathrm{m})$ unmyelinated axons are no longer seen and the remaining unmyclinated axons have thcir charactcristic narrow distribution around a mean of approximately $0.4 \mu \mathrm{m}$.

Between birth and P21 mean axon density in the entire corpus callosum drops from approximately 700 axons $/ 100 \mu \mathrm{m}^{2}$ to 350 axons $/ 100 \mu \mathrm{m}^{2}$ (Table 3 ). Axon density declines synchronously throughout the tract except for sector 10. In addition, the axon density and composition of sector 10 at birth does not reflect that in the adult, as is the case for the other sectors. At birth, sectors 1, 2, 3, and 10 have the highest axon density, approximately 1000 axons $/ 100 \mu \mathrm{m}^{2}$. During the 2 phases of axon elimination the proportional decline in axon density in sectors 2 through 8 is approximately 10 -fold (Table 4 ), while the proportional decline in sector 10 between birth and adulthood is twice the value found in all other sectors: approximately 20 fold. The rate of decline in axon density during the rapid phase of axon elimination in sector 10 is slower than in the other sectors (Table 4). Sector 10 does not attain its adult character (similar to that in sectors 6 and 7) until axon growth and myelination are complete.

\section{Discussion}

Our results address several issues concerning the development of interhemispheric connections: (1) To what extent do quantitative and cytological changes in the developing corpus callosum reflect the development and maturation of neurons that give rise to interhemispheric connections? (2) Do different classes of commissural axons originate from distinct classes of neurons and are they eliminated selectively? (3) Is the development of the primate corpus callosum comparable to that described for other species? (4) Can the onset, magnitude, and timing of axon addition and elimination in the corpus callosum be related to the emergence of specific patterns of interhemispheric connectivity in the cortex?

\section{Cytological changes in the developing corpus callosum}

The most reliable cytological indicator of axon addition in the corpus callosum is the presence of growth cones. We have identified 2 types of growth cones in the callosum: "round" and "lamcllatc." In scveral other regions of the devcloping mammalian CNS lamellate profiles have been identified as growth cones using electron microscopic serial reconstruction (Tennyson, 1970; Skoff and Hamburger, 1974; Shoukimas and Hinds, 1978; Williams and Rakic, 1985; Williams et al., 1986). In contrast, in previous studies the "round" processes have been considered either as growth cones and varicosities of growing axons (deKort et al., 1985) or as glial processes (Valentino and Jones, 1982; Jones, 1986). The results of electron microscopic serial reconstruction in the present study revealed the presence of both round and lamellate growth cones in the monkey corpus callosum. Although lamellate growth cones are encountered less frequently than round growth cones, neither class seems to be restricted to any region of the tract, apposed selectively to any particular cellular element, or to retain its neighbors for a significant distance. Thus, growing callosal axons, similar to the 


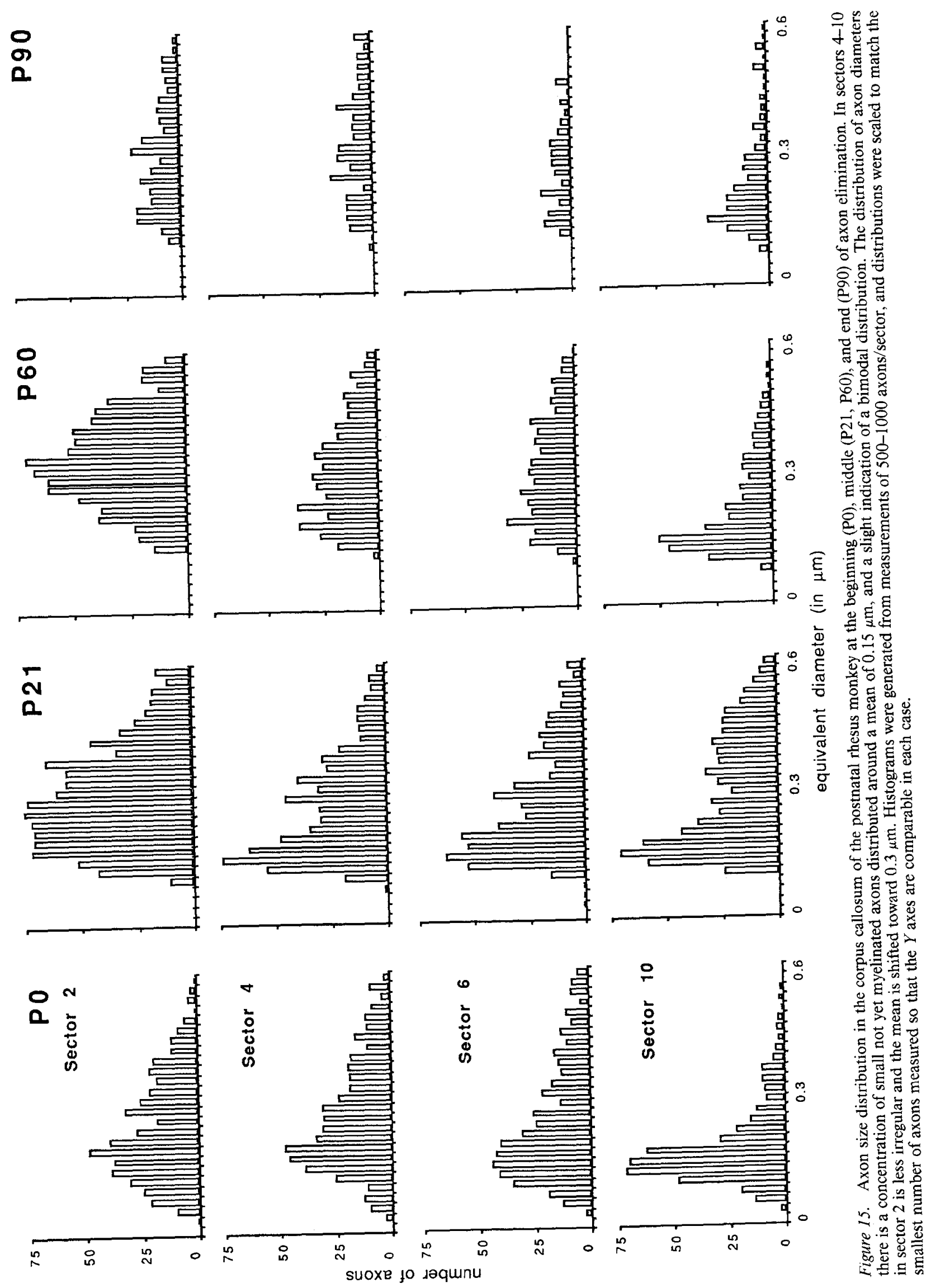




\begin{tabular}{llccccc}
\hline \multicolumn{2}{l}{ Table 4. Regional variation in axon density and myelination in sectors 2-10 of the corpus callosum } \\
Age & Parameter & Sector 2 & Sector 4 & Sector 6 & Sector 8 & Sector 10 \\
\hline P0 (mean of 2) & density & 1003 & 590 & 515 & 662 & 1141 \\
& \% myelinated & 0.0 & 1.4 & 3.9 & 3.4 & 0.9 \\
P5 & density & 339 & 264 & 208 & 296 & 341 \\
& \% myelinated & 0.1 & 4.3 & 8.9 & 8.2 & 4.9 \\
P14 & density & 606 & 461 & 249 & 355 & 449 \\
& \% myelinated & 0.0 & 4.3 & 11.7 & 9.1 & 4.9 \\
P22 & density & 291 & 219 & 151 & 186 & 231 \\
& \% myelinated & 1.3 & 9.5 & 16.5 & 15.2 & 12.8 \\
P60 & density & 346 & 1519 & 127 & 167 & 196 \\
& \% myelinated & 4.2 & 26.2 & 48.0 & 39.6 & 41.0 \\
P90 & density & 270 & 110 & 89 & 0 & 108 \\
& \% myelinated & 22.5 & 49.9 & 59.1 & 0 & 60.5 \\
P134 & density & 139 & 90 & 62 & 111 & 108 \\
& \% myelinated & 32.3 & 76.4 & 66.4 & 71.1 & 62.8 \\
Adult (mean of 5) & density & 120 & 80 & 57 & 58 & 57 \\
& \% myelinated & 72.6 & 90.0 & 92.9 & 94.0 & 96.4 \\
Density ratio: & & 8.36 & 7.38 & 9.04 & 10.72 & 20.02 \\
P0/adult & & & & & &
\end{tabular}

Axon density is given as $n$ axons/100 $\mu \mathrm{m}^{2}$. Adult density values represent the arithmetic mean of axon density values for sectors $2,4,6,8$, and 10 from 5 adult monkeys ranging in age from 3 years to adulthood (LaMantia and Rakic, 1990)

growing axons of the primate optic nerve (Williams and Rakic, 1985), do not maintain exclusive relationships with neighboring axons.

In some developing pathways, including the mammalian optic nerve, the elimination of supernumerary axons is accompanied by ultrastructural signs of axonal degeneration including electron-dense inclusions, dark granular cytoplasm, or accumulations of mitochondria (Webster, 1962; Lampert, 1967; Williams et al., 1986). We did not observe similar changes in the corpus callosum. However, a subset of unmyelinated axons appears to be swollen during the period of axon elimination. It is unlikely that this increase in diameter is related directly to myelination (Friede, 1972) since the most intense period of myelination in the corpus callosum occurs later than the time when these axons are seen. The swollen profiles in our material are reminiscent of those associated with axonal degeneration after axotomy (Mire et al., 1970), and may indicate the elimination of callosal axons due to retraction or cell death. There were few other signs of degenerative change within the corpus callosum at any age examined. We have not observed phagocytic cells in the midsagittal plane of the corpus callosum at any time during pre- or postnatal development, as described in the subcortical white matter of cats and rats during periods of callosal axon retraction or elimination (Valentino and Jones, 1981; Innocenti et al., 1983; Berbel and Innocenti, 1988).

\section{The emergence of axon segregation}

Regional variation in axon size and myelination is present at birth, before axon elimination begins. This indicates that the mosaic composition of axons in the corpus callosum (Pandya and Seltzer, 1986; LaMantia and Rakic, 1990) is probably not established by selective axon elimination. There is some evidence that a rough segregation of axons from different regions of the cortex can be detected quite soon after the first axons pass the midline in mice and rats (Hankin and Silver, 1984; Floerter and Jones, 1985). However, the potential existence of a cryptic wave of axon elimination that coincides with axon addition in the fetal monkey corpus callosum makes it difficult to rule out the possibility that some axons that find their way into inappropriate regions of the corpus callosum are eliminated at early prenatal stages. The presence of regional differences after birth in the monkey corpus callosum is in agreement with the finding that callosal axons from the visual cortex occupy roughly the same position in the neonatal and adult rat corpus callosum (Olavarria and Van Sluyters, 1985, 1986). In the rat the position of axons within the tract is stable even though the distribution of callosal neurons undergoes extensive reshaping during postnatal development (Olavarria and Van Sluyters, 1985). Thus, axon elimination may occur within groups of axons that are already in their correct location within the corpus callosum. The larger magnitude of postnatal decline in axon density in section 10 of the monkey, the primary visual component of the callosum, than all other sectors is surprising, particularly in light of the findings of Dehay et al. (1988) and Chalupa et al. (1989). This observation, however, indicates that distinct regions of the callosum may develop autonomously.

The earliest myelinated callosal axons are found in the primary sensory cortices, which in humans acquire myelin earlier than the association regions (Flechsig, 1920; Yakovlev and Lecours, 1967). In contrast, a recent study in the cat suggested that the corpus callosum becomes myelinated along an anterior-posterior gradient (Looney and Elberger, 1986; Bergel and Innocenti, 1988). Our study, in accordance with the earlier studies in the human, revealed that the maturation of distinct classes of callosal axons from anatomically or functionally distinct cortical regions procecds in a mosaic-like manner without following a continuous gradient.

\section{Changes in axon number and the emergence of patterned connections}

The number of axons in the developing rhesus monkey corpus callosum at birth is at least 3-4 times greater than the number 
found in the adult. The magnitude of overproduction is probably even greater if one considers that some elimination may occur during the phase of net axon addition and thus go unnoticed [for example, axons from subplate neurons (Chun et al., 1987)] These results in the monkey differ in several ways from those of similar studies in the rat and cat. Apparently, there is no net elimination of callosal axons in the rat, as judged by quantitative EM studies (Gravel et al., 1990), even though several retrograde studies (e.g., Ivy et al., 1979; O'Leary et al., 1981) indicate extensive reshaping of the patterns of callosal projections in the rodent. In contrast, a 2-3-fold overproduction of callosal axons has been reported for the cat (Koeppel and Innocenti, 1983; Berbel and Innocenti, 1988). Since in the cat, axon elimination seems to coincide with the establishment of adult patterns of visual, auditory, and somatosensory callosal projections (Innocenti and Caminiti, 1980; Innocenti, 1981; Feng and Brugge, 1983; Innocenti and Clarke, 1984; Innocenti et al., 1986), it has been proposed that quantitatively detectable axon elimination "sculpts" the adult topography of callosal connections by retraction or degeneration of "inappropriate" projections. This process has been suggested as a general mechanism for the establishment of interhemispheric connections (Innocenti, 1986; Berbel and Innocenti, 1988; Clarke et al., 1989).

Our results reveal that a correlation between the emergence of adult patterns of callosal projections and the detectable elimination of callosal axons does not exist in primates. In the rhesus monkey, the adult-like columnar organization of callosal terminal fields is first seen in sensory and association cortices between E100 and E130 (Goldman-Rakic et al., 1983; Killackey and Chalupa, 1986; Schwartz and Goldman-Rakic, 1990). This is 2 months before the major wave of postnatal axon elimination begins. Furthermore, as early as 2 months before birth, callosal neurons at the border of areas 17 and 18 are delimited to the positions they will occupy in the adult (Dehay et al., 1988). The reports of some "sculpting" of patterns of callosal projections in somatosensory and visual association areas in fetal monkeys between E108 and E133 (Killackey and Chalupa, 1986; Dehay et al., 1988) suggest that there may be instances of "exuberance" in the monkey. However, these instances occur too early and are quantitatively overwhelmed in the face of a massive net addition of axons. Therefore, they are unlikely to play a major role in the establishment of the final number of callosal axons. Whether or not these processes play a role in the initial shaping of patterns of callosal connections in some cortical areas-like the somatosensory and secondary visual association cortices (area 18)-but not others-like the primary visual and prefrontal cortices-cannot be addressed by our quantitative data.

Nevertheless, there is complete agreement that the adult-like pattern of callosal connections in the rhesus monkey is already in place when the number of axons in the callosum is at least 3 times greater than that in the adult. In fact, as many as 50 million axons may be added to the tract after adult-like patterns of callosal terminal fields are observable. Since no changes occur in the patterns or distribution of callosal neurons and terminal fields between birth and 5 months of age in all cortical regions examined thus far (Schwartz and Goldman-Rakic, 1982, 1990; Killackey and Chalupa, 1986; Dehay et al., 1986) it is unlikely that the postnatal elimination of axons could be involved in the sculpting of patterned callosal terminal fields or projection zones.

If the topographic distribution emerges before axon elimination begins, what is the significance of the massive reduction of axonal number in the infant rhesus monkey? The number of callosal axons in the rhesus monkey begins to decline after the subplate zone has already diminished in size (Kostovic and Rakic, 1990). Therefore, the dissolution of this transient embryonic zone probably does not play a significant quantitative role. One possible scenario is that many of the axons eliminated during the rapid phase belong to the earlier generated neurons situated in the infragranular cortical layers. This suggestion is supported by our finding that by E80 there are already 90 million callosal axons or more than half of the maximal number recorded and almost twice the number that will persist in the adult. At this age the neurons of layers II and III that form the bulk of callosal neurons in adult animals (Schwartz and Goldman-Rakic, 1984; Caminiti et al., 1985) have not yet been generated (Rakic, 1972, 1982, 1988). Thus, the first 90 million axons crossing the midline before E80 must belong to neurons situated in layers V and VI. Since these layers in adult primates contain less than $20 \%$ of callosal neurons (Schwartz and Goldman-Rakic, 1984; Caminiti et al., 1985) and therefore account for only 10 million of the 56 million callosal axons in the adult, it is reasonable to assume that between 70 and 80 million of these cells lose an interhemispheric axon or are eventually eliminated. Conversely, a larger proportion of later-generated callosal neurons, which settle in the supragranular layers II and III, may survive or retain interhemispheric axons. This sequence of events is consistent with both the sequencc of timc of ncuron origin and their final laminar position. It could potentially explain the magnitude of axonal elimination in the callosum and suggests that this may be a selective process.

Although our data suggest that infragranular callosal neurons may be eliminated in higher numbers than those in the supragranular layers, the intriguing question of whether axons that originate from the left and right side are eliminated in equal proportions remains unanswered. Lateralized differences in elimination of callosal axons might be related to the genesis of a wide range of functional and structural asymmetries in the primate cerebral cortex (for review, see Geschwind and Galaburda, 1985; Bleir et al., 1986). For example, one possibility is that lateralized differences in axon elimination result in a larger number of callosal projections from distinctive areas in the dominant hemisphere.

\section{Changes in axon number and synaptogenesis in the cortex}

The elimination of callosal axons may help shape local synaptic relationships between individual terminals and their targets rather than defining the gross topography of callosal projections. The temporal coincidence of callosal axon elimination and cortical synaptogenesis provides support for this hypothesis. The density of synaptic contacts per unit area of neuropil in the primate neocortex during postnatal development and in the adult is relatively uniform, regardless of the cortical region or layer (Bourgeois and Rakic, 1983; Rakic et al., 1986; Zecevic et al., 1989). Even in animals with experimentally altered afferent input, synapse density throughout the cortex is maintained at normal levels (Bourgeois and Rakic, 1987; Rakic, 1988; Bourgeois et al., 1989). This consistency of synaptic density may influence the establishment of the final number of callosal axons. Limits on synapse density, mediated perhaps by metabolic, hormonal, or trophic mechanisms, may determine the number of functionally relevant synaptic connections formed by cortical projections, including callosal axons.

During the first two postnatal months when the magnitude 
and rate of callosal axon loss is the greatest, new synapses are added rapidly to all layers in all cortical areas (Rakic et al., 1986). Similar temporal relationships between the disappearance of multiple innervation of muscle fibers or parasympathetic ganglion cells and morphological synapse formation have been observed in the PNS (Brown et al., 1976; Lichtman, 1977; Purves and Lichtman, 1980). One can speculate that functionally viable callosal axons may begin to elaborate synaptic contacts while supernumerary axons are being withdrawn (Innocenti, 1981; O'Leary et al., 1981) either because they failed to establish synaptic connections with target neurons or because the cortical neurons that give rise to them are dying as a result of a lack of appropriate innervation or trophic support (Rakic, 1977, 1986; Finlay and Slattery, 1983; Williams et al., 1987; Purves, 1988). Whether or not the supernumerary axons in the monkey represent axon collaterals that are lost or single axons of cells that die remains to be determined. Furthermore, the extent to which overproduction and elimination of supernumerary axons influences the development of cortical projections other than callosal projections remains to be defined. In the primate cerebral cortex, axon elimination does not appear to be limited to callosal projections since we have observed similar phenomena in the anterior and hippocampal commissures (LaMantia and Rakic, unpublishcd obscrvations). Each instancc of climination occurs at a time when the brain is primed for interactions which may influence the final numbers and patterns of synaptic connections.

\section{References}

Berbel P, Innocenti GM (1988) The development of the corpus callosum in cats. A light and electron microscopic study. J Comp Neurol 276:132-156.

Bleir R, Houston L, Byne W (1986) Can the corpus callosum predict gender, age, handedness, or cognitive differences? Trends Neurosci 9: 391-394.

Bourgeois J-P, Rakic P (1983) Synaptogenesis in the primary visual cortex: quantitative analysis in pre- and postnatal rhesus monkeys. Soc Neurosci Abstr 9:692.

Bourgeois J-P, Kakic P (1987) Distribution, density and ultrastructure of synapsis in the visual cortex of rhesus monkeys devoid of retinal input from early embryonic stages. Soc Neurosci Abstr 13:1044.

Bourgeois J-P, Jastreboff P, Rakic P (1989) Synaptogenesis in the visual cortex of normal and preterm monkeys: evidence for intrinsic regulation of synaptic overproduction. Proc Natl Acad Sci USA 86: 4297-4301.

Brown MC, Jansen JKS, Van Essen D (1976) Polyneuronal innervation of skeletal muscle in newborn rats and its elimination during maturation. J Physiol (Lond) 261:387-422.

Caminiti R, Zeger S, Johnson PB, Urbano A, Georgopolous AP (1985) Cortico-cortical efferent systems in the monkey: a quantitative spatial analysis of the tangential distribution of cells of origin. J Comp Neurol 241:405-419.

Chalupa LM, Killackey HP (1989) Process elimination underlies ontogenetic change in the distribution of callosal projection neurons in the post-central gyrus of the fetal rhesus monkey. Proc Natl Acad Sci USA 86:1076-1079.

Chalupa LM, Killackey HP, Snider CJ, Lia B (1989) Callosal projection neurons in area 17 of the fetal rhesus monkey. Dev Brain Res 46:303-309.

Chun JJM, Nakamura MJ, Shatz CJ (1987) Transient cells of the developing mammalian telencephalon are peptide immunoreactive neurons. Nature 325:617-620.

Clarke S, Kraftsik R, VanderLoos H, Innocenti GM (1989) Forms and measures of adult and developing human corpus callosum: is there sexual dimorphism? J Comp Neurol 280:213-230.

Cowan, WM, Fawcett JW, O'Leary DDM, Stanfield BB (1984) Regressive events in neurogenesis. Science 225:1258-1265.
Dehay C, Kennedy H, Bullier J (1986) Callosal connectivity of areas $\mathrm{V} 1$ and V2 in the newborn monkey. J Comp Neurol 254:20-30.

Dehay C, Kennedy H, Bullier J, Berland M (1988) Absence of interhemispheric connections of area 17 during development in the monkey. Nature 331:348-350.

deKort EJM, Gribnau AAM, van Aanholt HTH, Nieuwenhuys R (1985) On the development of the pyramidal tract in the rat. I. The morphology of the growth zone. Anat Embryol 172:195-204.

Easter SS Jr, Rusoff AC, Kish PE (1981) The growth and organization of the optic nerve and tract in juvenile and adult goldfish. J Neurosci $1: 793-811$.

Feng J, Brugge JF (1983) Postnatal development of auditory callosal connections in the kitten. J Comp Neurol 214:416-426.

Finlay B, Slattery M (1983) Local differences in the amount of early cell death in ncocortex predict adult local spccializations. Science 219: 1349-1351.

Flechsig P (1920) Anatomie des menschichen Gehirns und Ruckenmarks auf myelogenetischer Grundlage. Leipzig: George Thieme.

Floerter MK, Jones EG (1985) The morphology and phased outgrowth of callosal axons in the fetal rat. Dev Brain Res 22:7-18.

Friede RL (1972) Control of myelin formation by axon caliber (with a model of the control mechanism). $\mathbf{J}$ Comp Neurol 144:233-252.

Geschwind N, Galaburda AM (1985) Cerebral lateralization: biological mechanisms, associations, and pathology. I. A hypothesis and a program for research. Arch Neurol 42:428-459.

Goldman-Rakic PS, Iseroff A, Schwartz ML, Bugbee NM (1983) The neurobiology of cognitive development. In: Handbook of child psychology: biology and infancy development (Mussen P, ed.), pp 281344. New York: Wilcy.

Gravel C, Sasseville R, Hawkes R (1990) Maturation of the corpus callosum of the rat: II. Influence of thyroid hormones on the number and maturation of axons. J Comp Neurol 291:147-161.

Gunderson HJG (1977) Notes on the elimination of the numerical density of arbitrary profiles: the edge effect. J. Microscopy III:219223.

Hankin MJ, Silver J (1984) The role of the environment in guiding intersecting axon tracts in the mammalian telencephalon. Soc Neurosci Abstr 10:372.

Innocenti GM (1981) Growth and reshaping of axons in the establishment of visual callosal connections. Science 212:824-827.

Innocenti GM (1986) What is so special about callosal connections? In: Two hemispheres, one brain: functions of the corpus callosum. Lepore $\Gamma$, Ptito M, Jasper HH, eds), pp. 75-81. New York: Liss.

Innocenti GM, Caminiti R (1980) Postnatal shaping of callosal connections from sensory areas. Exp Brain Res 38:381-394.

Innocenti GM, Clarke S (1984) The organization of immature callosal connections. J Comp Neurol 230:287-309.

Innocenti GM, Fiore L, Caminiti R (1977) Exuberant projection into the corpus callosum from the visual cortex of newborn cats. Neurosci Lett 4:237-242.

Innocenti GM, Clarke S, Koeppel H (1983) Transitory macrophages in the white matter of the developing visual cortex. II. Development and relations with axon pathways. Dev Brain Res 11:55-66.

Innocenti GM, Clarke S, Kraftsik R (1986) Interchange of callosal and associational projections in the developing visual cortex. J Neurosci 6:1384-1409.

Ivy GO, Killackey IIP (1982) Ontogenetic changes in the projections of neocortical neurons. J Neurosci 2:735-743.

Ivy GO, Akers RM, Killackey HP (1979) Differential distribution of callosal projection neurons in the neonatal and adult rat. Brain Res 173:532-537.

Jones EG (1986) Corpus callosum-one system, two approaches. In: Two hemispheres, one brain: functions of the corpus callosum (Lepore F, Ptito M, Jasper HH, eds), pp 149-164. New York: Liss.

Killackey HP, Chalupa LM (1986) Ontogenetic change in the distribution of callosal projection neurons in the post-central gyrus of the fetal rhesus monkey. J Comp Neurol 244:331-348.

Koeppel H, Innocenti GM (1983) Is there a genuine exuberancy of callosal projections in development? A quantitative electron microscopic study in the cat. Neurosci Lett 41:33-40.

Kostovic I, Rakic P (1990) Developmental history of the transient subplate zone in the visual and somatosensory cortex of the macaque monkey and human brain. J Comp Neurol (in press).

LaMantia A-S, Rakic P (1990) A cytological and quantitative char- 
acterization of four cerebral commissures in the adult rhesus monkey. J Comp Neurol 291:520-537.

Lampert PW (1967) A comparative electron microscopic study of reactive, degenerating, regenerating, and dystrophic axons. J Neuropath Exp Neurol 26:345-368.

Lichtman J (1977) The reorganization of synaptic connections in the rat submandibular ganglion during postnatal development. J Physiol 273:155-177.

Linden R, Perry VH (1982) Ganglion cell death within the developing retina: a regulatory role for developing retinal dendrites? Neuroscience 7:2813-2827.

Looney GA, Elberger AJ (1986) Myelination of the corpus callosum in the cat: time course, topography, and functional implications. $J$ Comp Neurol 248:336-347.

Mire JJ, Hendelman WJ, Bunge RP (1970) Observations on a transient phase of focal swelling in degenerating unmyelinated nerve fibers. J Cell Biol 45:9-22.

Mori S, Leblond CP (1970) Electron microscopic identification of the classes of oligodendrocytes and a preliminary study of their proliferative activity in the corpus callosum of young rats. J Comp Neurol 137:197-226.

O'Leary DDM, Stanfield B, Cowan WM (1981) Evidence that the early postnatal restriction of the cells of origin of the corpus callosal projections is due to the elimination of axon collaterals rather than to the death of neurons. Dev Brain Res 1:607-617.

Olavarria J, Van Sluyters RC. (1985) Organization and postnatal development of callosal connections in the visual cortex of the rat. $J$ Comp Neurol 239:1-26.

Olavarria J, Van Sluyters RC (1986) Axons from resticted regions of the cortex pass through restricted portions of the corpus callosum in adult and neonatal rats. Dev Brain Res 25:309-313.

Pandya DN, Seltzer B (1986) The topography of commissural fibers. In: Two hemispheres, one brain, functions of the corpus callosum (Lepore F, Ptito M, Jasper HH, eds), pp 47-73. New York: Liss.

Perry VH, Henderson Z, Linden R (1983). Postnatal changes in retinal ganglion cell and optic axon populations in the pigmented rat. J Comp Neurol 219:356-368.

Purves D (1988) Body and brain: a trophic theory on neural connections. Cambridge, MA: Harvard.

Purves D, Lichtman JW (1980) Elimination of synapses in the developing nervous system. Science 210:153-157.

Rager G, Rager U (1976) Generation and degeneration of retinal ganglion cclls in the chicken. Exp Brain Res 25:551-553.

Rakic P (1972) Mode of cell migration to the superficial layers of fetal monkey neocortex. J Comp Neurol 145:61-84.

Rakic P (1976) Prenatal genesis of connections subserving ocular dominance in the rhesus monkey. Nature 261:467-471.

Rakic P (1977) Prenatal development of the visual system in rhesus monkey. Phil Trans R Soc (Lond) 278:245-260.

Rakic P (1982) Early events: cell lineages, acquisition of neuronal position, and areal and laminar development. In: NRP bull 20: development and modifiability of the cerebral cortex: 438-451.

Rakic P (1986) Mechanisms of ocular dominance segregation in the lateral geniculate nucleus: competitive elimination hypothesis. Trends Neurosci 9:11-15.

Rakic P (1988) Specification of cerebral cortical areas. Science 241: 170-176.

Rakic P, Goldman-Rakic PS (1982) Development and modifiability of the cerebral cortex. Overview. NRP Bull 20:433-438.
Rakic P, Riley KP (1983) Overproduction and elimination of retinal axons in the fetal rhesus monkey. Science 219:1441-1444.

Rakic P, Yakovlev PI (1968) Development of the corpus callosum and cavum septi in man. $J$ Comp Neurol 132:45-72.

Rakic P, Bourgeois J-P, Eckenhoff MEF, Zecevic N, Goldman-Rakic PS (1986) Concurrent overproduction of synapses in diverse regions of the primate cerebral cortex. Science 232:232-235.

Schwartz ML, Goldman-Rakic PS (1982) Single cortical neurons have axon collateral to ipsilateral and contralateral cortex in fetal and adult primates. Nature 299:154-156.

Schwartz ML, Goldman-Rakic PS (1984) Callosal and intrahemispheric connectivity of the prefrontal association cortex in rhesus monkey: relation between intraparietal and principal sulcal cortex. J Comp Neurol 226:403-420.

Schwartz ML, Goldman-Rakic PS (1990) Early specification of callosal connections in the fetal monkey prefrontal cortex. J Comp Neurol (in press).

Shoukimas GM, Hinds JW (1978) The development of the cerebral cortex in the embryonic mouse: an electron microscopic serial section analysis. J Comp Neurol 179:795-830.

Skoff RP, Hamburger V (1974) Fine structure of dendritic and axonal growth cones in embryonic chick spinal cord. J Comp Neurol 153: 107-147.

Snedecor GW, Cochran WG (1977) Statistical methods. Chap. 17 in: Design and analysis of sampling, pp 504-539. Ames, IA: Iowa State UP.

Tennyson VM (1970) The fine structure of the axon and growth cone of the dorsal root neuroblast of the rabbit embryo. J Cell Biol 44:6279.

Valentino KL, Jones EG (1981) Morphological and immunocytochemical identification of macrophages in the developing corpus callosum. Anat Embryol 163:157-172.

Valentino KL, Jones EG (1982) The early formation of the corpus callosum. A light and electron microscopic study of foetal and neonatal rats. J Neurocytol 11:583-609.

Walsh C, Guillery RW (1985) Age related fiber order in the optic tract of the ferret. J Neurosci 5:3061-3069.

Webster $\mathrm{H}$ deF (1962) Transient focal accumulation of axonal mitochondria during the early stages of Wallerian degeneration. J Cell Biol 12:361-383.

Williams RW, Rakic P (1985) Dispersion of growing axons within the optic nerve of the embryonic monkey. Proc Natl Acad Sci USA 82: 3906-3910.

Williams RW, Rakic P (1988) Elimation of neurons in rhesus monkey's geniculate nucleus during development. J Comp Neurol 272 : 424-436.

Williams RW, Bastiani MJ, Lia B, Chalupa LM (1986) Growth cones, dying axons and developmental fluctuation in the fiber population of the cat's optic nerve. J Comp Neurol 246:32-69.

Williams RW, Ryder K, Rakic P (1987) Emergence of cytoarchitectonic differences between areas 17 and 18 in the developing rhesus monkey. Soc Neurosci Abstr 13:1044.

Yakovlev PI, Lecours AR (1967) The myelogenetic cycles of regional maturation of the brain. In: Regional development of the brain in early life (Minkowski A, ed). Oxford, UK: Blackwell.

Zecevic N, Bourgeois J-P, Rakic P (1989) Changes in synaptic density in motor cortex during fetal and postnatal life. Dev Brain Res 50:1132. 